\title{
Long-term trends of per- and polyfluoroalkyl substances (PFAS) in German rivers using the direct total oxidizable precursor (dTOP) assay
}

Bernd Göckener ${ }^{1 *}$, Annette Fliedner ${ }^{1}$, Heinz Rüdel ${ }^{1}$, Alexander Badry ${ }^{2}$, Jan Koschorreck ${ }^{2}$

${ }^{1}$ Fraunhofer Institute for Molecular Biology and Applied Ecology (Fraunhofer IME), 57392

Schmallenberg, Germany

${ }^{2}$ German Environment Agency (Umweltbundesamt), 06813 Dessau-Rosslau, Germany

*Corresponding author: bernd.goeckener@ime.fraunhofer.de; phone: +49 2972302 182; fax: +49

2972302319

\section{Contents:}

Text: $\quad$ Chemical Analysis

Table S1: $\quad$ Characteristics of sampling sites

Table S2: $\quad$ List of targeted compounds

Figure S1: Verification of model assumptions for Gaussian GLM (identity link) on loge transformed $\sum_{13}$ PFCA concentrations measured by target analytics

Figure S2: $\quad$ Verification of model assumptions for Gaussian GLM (identity link) on $\log _{\mathrm{e}}$ transformed $\Sigma_{13}$ PFCA concentrations measured by dTOP assay

Figure S3: Verification of model assumptions for Gaussian GLM (identity link) on loge transformed $\sum_{8}$ PFSA concentrations measured by target analytics

Table S3: $\quad$ Estimates of the fixed effects on $\log _{\mathrm{e}}$-concentrations of $\sum_{8} \mathrm{PFSA}$ excluding the outlier Prossen 2019 (Elbe)

Figure S4: Verification of model assumptions for Gaussian GLM (identity link) on loge transformed $\Sigma_{8} \mathrm{PFSA}$ concentrations measured by dTOP assay with (A) and without (B) the outlier Prossen 2019 (Elbe) 
Figure S5: Verification of model assumptions for Gaussian GLM (identity link) on loge transformed $\sum \mathrm{C}_{4}-\mathrm{C}_{7}$ PFCA concentrations measured by dTOP assay

Figure S6: Verification of model assumptions for Gaussian GLM (identity link) on loge transformed $\mathrm{CC}_{8}-\mathrm{C}_{18} \mathrm{PFCA}$ concentrations measured by dTOP assay

Figure S7: $\quad$ Target analysis: PFAS concentrations ( $\mu \mathrm{g} \mathrm{kg}^{-1} \mathrm{dry}$ weight) and patterns in suspended particulate matter

Figure S8: $\quad$ Target analysis: Concentrations ( $\mu \mathrm{g} \mathrm{kg}^{-1} \mathrm{dry}$ weight) of diPAP in suspended particulate matter from the sampling sites

Figure S9: $\quad$ dTOP assay: PFCA concentrations ( $\mu \mathrm{g} \mathrm{kg}^{-1}$ dry weight) and patterns in suspended particulate matter

Figure S10: $\quad$ Predictor effects plots showing the spatial differences of $\sum_{13} \mathrm{PFCA}$ and $\sum_{8} \mathrm{PFSA}$ concentrations ( $\mu \mathrm{g} \mathrm{kg}^{-1} \mathrm{dry}$ weight) in suspended particulate matter from German rivers with fixed values for 'year' and 'TOC'

Table S4: $\quad$ Results of the generalized linear modelling of short- and long-chain PFCA $\left(\sum \mathrm{C}_{4}-\mathrm{C}_{7}\right.$ PFCA and $\sum \mathrm{C}_{8}-\mathrm{C}_{18}$ PFCA)

Figure S11: $\quad$ Predictor effects plots for $\sum C_{4}-C_{7}$ and $\sum C_{8}-C_{18}(+1)$ PFCA concentrations $\left(\mu \mathrm{g} \mathrm{kg}^{-1} \mathrm{dry}\right.$ weight) in suspended particulate matter from German rivers

Table S5: $\quad$ Physicochemical characteristics of the SPM samples

Figure S12: Range of total organic carbon (TOC) contents and pH-values in suspended particulate matter sampled between 2005 and 2019 in German rivers

Figure S13: Predictor effects plots showing the influence of total organic carbon (TOC) content on $\Sigma_{13} \mathrm{PFCA}$ and $\Sigma_{8} \mathrm{PFSA}$ concentrations ( $\mu \mathrm{g} \mathrm{kg}^{-1} \mathrm{dry}$ weight) in suspended particulate matter from German rivers with fixed values for 'year' and 'river'

Table S6: $\quad$ Calculated annual PFAS loads in SPM from the first year and in 2017 and 2019 of the study period

Figure S14: Annual PFAS loads $\left(\mathrm{kg} \mathrm{a}^{-1}\right)$ of suspended particulate matter (SPM) in the Rhine in 2005 and 2019

Figure S15: Annual PFAS loads $\left(\mathrm{kg} \mathrm{a}^{-1}\right)$ of suspended particulate matter (SPM) in the Elbe in 2005 and 2019 


\section{Chemical analysis}

\section{Standards and reagents}

Analytical PFAS standards and internal standards were obtained from Wellington Laboratories (Ontario, Canada). Ultra high quality (UHQ) water was purified with a Purelab Ultra system from ELGA (Wycombe, United Kingdom). LC-MS grade methanol and sodium hydroxide from Chemsolute (Th. Geyer, Renningen, Germany) were used. Tetrabutylammonium hydrogensulfate ( $\geq 99 \%$ ) and ammonium acetate for LC-MS were purchased from Sigma Aldrich (St. Louis, USA). Ammonia, sodium carbonate, and sodium bicarbonate (p.A.) were obtained from Merck (Darmstadt, Germany) and methyl tert-butyl ether was purchased from Honeywell (Seelze, Germany). Hydrochloric acid was obtained from J.T. Baker (Avantor, Radnor, USA) and potassium persulfate ( $\geq 99 \%)$ was purchased from Acros Organics (Fair Lawn, USA).

\section{Target analysis}

The method used for target analysis was described in detail by Kotthoff et al. ${ }^{1}$ and modified accordingly to lower the LOQs. For sample preparation, $5 \mathrm{~g}$ of homogenized and freeze-dried sample was amended with $100 \mu \mathrm{L}$ of a methanolic solution of internal standards ( $100 \mu \mathrm{g} \mathrm{L}^{-1}$ each) and $10 \mathrm{~mL}$ of a buffering solution ( $0.25 \mathrm{M}$ sodium carbonate, $0.25 \mathrm{M}$ sodium hydrogen carbonate) and $10 \mathrm{~mL}$ methyl-tert-butylether were added. The samples were shaken for $10 \mathrm{~min}$ on a horizontal shaker before being treated in an ultrasonic bath for another $20 \mathrm{~min}$.

After centrifugation at $4700 \mathrm{rpm}$ for $5 \mathrm{~min}$, the organic phase was transferred into a $15 \mathrm{~mL}$ centrifuge tube and the solvent was evaporated to dryness under a gentle stream of nitrogen at $40{ }^{\circ} \mathrm{C}$. The residue was then resuspended in $500 \mu \mathrm{L}$ methanol by vortexing ( $5 \mathrm{~min}$ ) and treatment in an ultrasonic bath ( $5 \mathrm{~min}$ ). Analysis was performed using ultra-high performance liquid chromatography (UHPLC, Waters Acquity UPLC system (Water Corporation (Milford, MA, USA))) coupled to a highresolution mass spectrometer (HRMS, Q Exactive Plus system, Thermo Fisher Scientific, Waltham, MA, USA). Data were obtained in negative ionization mode in Fullscan mode coupled with an All-IonFragmentation (FullMS-AIF). Further details on the data acquisition were as described by Kotthoff et al. ${ }^{1}$.

\section{Direct TOP assay (dTOP)}

The dTOP assay method described by Göckener et al. ${ }^{2}$ was further adapted to the matrix SPM. For this, $250 \mathrm{mg}$ of a homogenized and freeze-dried sample were weighed into $250 \mathrm{~mL}$ PP bottles and were spiked with internal standards of PFAA. $200 \mathrm{~mL}$ of an oxidation solution ( $200 \mathrm{mM}$ potassium persulfate and $500 \mathrm{mM}$ sodium hydroxide) were added and the samples were oxidized by heating at $85^{\circ} \mathrm{C}$ for $7 \mathrm{~h}$ in a drying cabinet. After cooling down to room temperature, samples were neutralized and a solid phase extraction (SPE) was performed as described by Göckener et al. ${ }^{2}$. Additionally the neutralized oxidation solutions were centrifuged in $50 \mathrm{~mL}$ PP tubes in order to apply the clear solution to the SPE column first. Finally, the remaining inorganic SPM material was loaded onto the SPE column with $5 \mathrm{~mL}$ water and $5 \mathrm{~mL}$ methanol/water $(50 / 50, \mathrm{v} / \mathrm{v})$ as washing solutions. The rest of the SPE procedure and the final analysis via UHPLC-HRMS was as described by Göckener et al. ${ }^{2}$. 
Table S1: Characteristics of the Environmental Specimen Bank sampling sites for suspended particulate matter (Fliedner et al. ${ }^{3}$, modified)

\begin{tabular}{|c|c|c|c|c|}
\hline River & $\begin{array}{l}\text { Sampling } \\
\text { site }\end{array}$ & acronym & River km & Short characterization of the sites \\
\hline \multirow[t]{3}{*}{ Rhine } & Weil & R1 & 174 & $\begin{array}{l}\text { Site in the Upper Rhine at the entry into the Upper Rhine Valley and the beginning of the Rhine canal, located at the Swiss- } \\
\text { German border just downstream of the city of Basel; captures the contamination load of the industries in the Basel area. } \\
\text { Sampling in stream. }\end{array}$ \\
\hline & Koblenz & R3 & 590 & $\begin{array}{l}\text { Site in the Middle Rhine after the rivers has crossed the Rhenish Slate Mountains and directly upstream of the Moselle } \\
\text { confluence, about } 4 \mathrm{~km} \text { downstream of the Lahn confluence and } 100 \mathrm{~km} \text { downstream of the Rhine-Main conurbation; } \\
\text { reflects the pollution of the Middle Rhine. Sampling in measuring station. }\end{array}$ \\
\hline & Bimmen & $\mathrm{R} 4$ & 865 & $\begin{array}{l}\text { Site in the Lower Rhine along the German-Dutch border about } 85 \mathrm{~km} \text { and } 50 \mathrm{~km} \text { downstream of the Ruhr and Lippe } \\
\text { confluences; captures the contaminant load of the Rhine downstream of the industrial region of the Ruhr conurbation. } \\
\text { Sampling in measuring station. }\end{array}$ \\
\hline \multirow{2}{*}{$\begin{array}{l}\text { Saar / } \\
\text { tributary } \\
\text { of the } \\
\text { Rhine }\end{array}$} & Guedingen & S1 & $\begin{array}{c}\text { barrage } \\
\text { Guedingen }\end{array}$ & $\begin{array}{l}\text { Site in the area of the barrage of Guedingen at the entry of the Saar into the Saar conurbation directly downstream of the } \\
\text { French-German border, influenced by the } 2 \text { nd largest sewage treatment plant of the Saarland; reflects the contaminant } \\
\text { load of the Saar upstream of the industrial Saar conurbation. Sampling in stream. }\end{array}$ \\
\hline & Rehlingen & $\mathrm{S} 2$ & $\begin{array}{l}\text { barrage } \\
\text { Rehlingen }\end{array}$ & $\begin{array}{l}\text { Site located in the area of the barrage of Rehlingen, where the Saar leaves the Saarland conurbation, directly downstream } \\
\text { of the industrial area of the cities of Dillingen / Voelklingen and } 20 \mathrm{~km} \text { downstream of the Rossel mouth; influenced by a } \\
\text { sewage treatment plant, captures the contamination of the Saar downstream of the industrial sites of the Saar } \\
\text { conurbation. Sampling in stream. }\end{array}$ \\
\hline \multirow[t]{4}{*}{ Elbe } & Prossen & E1 & 13 & $\begin{array}{l}\text { Site in the upper reach of the Elbe shortly downstream of the Czech-German border; designed to study the contaminant } \\
\text { load of the Elbe at its entry to Germany. Sampling in stream. }\end{array}$ \\
\hline & Zehren & E2 & 96 & $\begin{array}{l}\text { Site in the transition area between upper and middle section of the Elbe about } 30 \mathrm{~km} \text { downstream of the city of Dresden } \\
\text { and } 5 \mathrm{~km} \text { downstream of Meissen; reflects the water pollution of the urban area of Dresden. Sampling in measuring } \\
\text { station. }\end{array}$ \\
\hline & Cumlosen & E4 & 470 & $\begin{array}{l}\text { Site in the relatively natural section of the Middle Elbe in the North German Plain; reflects the pollution at the former cold } \\
\text { war German-German border and the industries at the city of Magdeburg. Sampling in measuring station. }\end{array}$ \\
\hline & Blankenese & E5 & 632 & $\begin{array}{l}\text { Site in the tidal section of the Lower Elbe located downstream of the city of Hamburg and the Hamburg harbor; documents } \\
\text { the contaminant load discharged into the North Sea. Sampling in measuring station. }\end{array}$ \\
\hline $\begin{array}{l}\text { Saale / } \\
\text { tributary } \\
\text { of the } \\
\text { Elbe }\end{array}$ & Saale & Sa & near mouth & $\begin{array}{l}\text { Site between the harbor of Halle and the barrage at Wettin; reflects the contaminant load of the Halle conurbation } \\
\text { discharged into the Elbe. Sampling in stream. }\end{array}$ \\
\hline
\end{tabular}




\begin{tabular}{|c|c|c|c|c|}
\hline River & $\begin{array}{l}\text { Sampling } \\
\text { site }\end{array}$ & acronym & River km & Short characterization of the sites \\
\hline $\begin{array}{l}\text { Mulde / } \\
\text { tributary } \\
\text { of the } \\
\text { Elbe }\end{array}$ & Mulde & $\mathrm{Mu}$ & Near mouth & $\begin{array}{l}\text { Site in the Jonitzer Mulde and Mulde between the branch off of the Jonitzer Mulde and the confluence with the Elbe at } \\
\text { Dessau-Rosslau; about } 20 \mathrm{~km} \text { downstream of the city of Bitterfeld; captures the contamination of the industrial area } \\
\text { around Bitterfeld discharged into the Elbe. Sampling in measuring station. }\end{array}$ \\
\hline \multirow[t]{2}{*}{ Danube } & Ulm & D1 & 2593 & $\begin{array}{l}\text { Site in the reservoir basins at a barrage in the headwaters of the Danube below the Swabian Jura, downstream of the } \\
\text { villages of Ehingen and Erbach; reflects the water quality of the near natural part of the river. Sampling in stream }\end{array}$ \\
\hline & Jochenstein & D3 & 2210 & $\begin{array}{l}\text { Site in the Middle Danube at the German-Austrian border about } 20 \mathrm{~km} \text { downstream of the Inn confluence; reflects the } \\
\text { contaminant load of the Danube when leaving Germany. Sampling in stream. }\end{array}$ \\
\hline
\end{tabular}


Table S2: List of targeted compounds and limits of quantification (LOQs) achieved in target analysis and dTOP assay.

\begin{tabular}{|c|c|c|c|c|c|}
\hline \multirow[t]{2}{*}{ class } & \multirow[t]{2}{*}{ acronym } & \multirow[t]{2}{*}{ name } & \multirow[t]{2}{*}{ CAS } & \multicolumn{2}{|c|}{$\begin{array}{l}\text { LOQ } \\
\text { ( } \mu \mathrm{g} \mathrm{kg}{ }^{-1} \text { dry weight) }\end{array}$} \\
\hline & & & & target & dTOP \\
\hline \multirow{13}{*}{$\begin{array}{l}\text { Perfluoroalkyl } \\
\text { carboxylic acids } \\
\text { (PFCA) }\end{array}$} & PFBA & Perfluorobutanoic acid & $375-22-4$ & 0.5 & 1.0 \\
\hline & PFPA & Perfluoropentanoic acid & $45167-47-3$ & 0.5 & 1.0 \\
\hline & PFHxA & Perfluorohexanoic acid & $307-24-4$ & 0.05 & 1.0 \\
\hline & PFHpA & Perfluoroheptanoic acid & $375-85-9$ & 0.5 & 1.0 \\
\hline & PFOA & perfluorooctanoic acid & $335-67-1$ & 0.05 & 1.0 \\
\hline & PFNA & Perfluorononanoic acid & $375-95-1$ & 0.05 & 1.0 \\
\hline & PFDA & Perfluorodecanoic acid & $335-76-2$ & 0.05 & 1.0 \\
\hline & PFUnDA & Perfluoroundecanoic acid & $2058-94-8$ & 0.05 & 1.0 \\
\hline & PFDoA & Perfluorododecanoic acid & $307-55-1$ & 0.5 & 1.0 \\
\hline & PFTrDA & Perfluorotridecanoic acid & $72629-94-8$ & 0.5 & 1.0 \\
\hline & PFTeDA & Perfluorotetradecanoic acid & $376-06-7$ & 0.5 & 1.0 \\
\hline & PFHxDA & Perfluorohexadecanoic acid & $67905-19-5$ & 0.5 & 1.0 \\
\hline & PFODA & Perfluorooctadecanoic acid & $16517-11-6$ & 0.5 & 1.0 \\
\hline \multirow{8}{*}{$\begin{array}{l}\text { Perfluoroalkyl } \\
\text { sulfonic acids } \\
\text { (PFSA) }\end{array}$} & PFBS & Perfluorobutane sulfonic acid & $375-73-5$ & 0.05 & 1.0 \\
\hline & PFPeS & Perfluoropentane sulfonic acid & $630402-22-1$ & 0.05 & 1.0 \\
\hline & PFHxS & Perfluorohexane sulfonic acid & $355-46-4$ & 0.05 & 1.0 \\
\hline & PFHpS & Perfluoroheptane sulfonic acid & $375-92-8$ & 0.5 & 1.0 \\
\hline & $\begin{array}{l}\text { PFOS } \\
\text { linear }\end{array}$ & Perfluorooctane sulfonic acid & $1763-23-1$ & 0.05 & 1.0 \\
\hline & $\begin{array}{l}\text { PFOS } \\
\text { branched }\end{array}$ & Perfluorooctane sulfonic acid & - & 0.05 & 1.0 \\
\hline & PFNS & Perfluorononane sulfonic acid & 474511-07-4 & 0.05 & 1.0 \\
\hline & PFDS & Perfluorodecane sulfonic acid & $335-77-3$ & 0.05 & 1.0 \\
\hline \multirow{3}{*}{$\begin{array}{l}\text { fluorotelomer } \\
\text { sulfonic acids }\end{array}$} & $4: 2-\mathrm{FtS}$ & 4:2 Fluorotelomer sulfonic acid & $757124-72-4$ & 0.05 & - \\
\hline & $6: 2-\mathrm{FtS}$ & 6:2 Fluorotelomer sulfonic acid & 27619-97-2 & 0.05 & - \\
\hline & $8: 2-\mathrm{FtS}$ & $8: 2$ Fluorotelomer sulfonic acid & $39108-34-4$ & 0.05 & - \\
\hline \multirow[t]{3}{*}{$\begin{array}{l}\text { Perfluoroalkane } \\
\text { sulfonamides }\end{array}$} & $\begin{array}{l}\text { FOSA } \\
\text { (PFOSA) }\end{array}$ & Perfluorooctane sulfonaminde & $754-91-6$ & 0.05 & - \\
\hline & N-MeFOSA & $\begin{array}{l}\text { N-methyl perfluorooctane } \\
\text { sulfonamide }\end{array}$ & $31506-32-8$ & 0.5 & - \\
\hline & N-EtFOSA & $\begin{array}{l}\text { N-Ethyl-perfluorooctane } \\
\text { sulfonamide }\end{array}$ & $4151-50-2$ & 0.5 & - \\
\hline \multirow{3}{*}{$\begin{array}{l}\text { Perfluoroalkane } \\
\text { sulfonamido } \\
\text { acetic acids }\end{array}$} & FOSAA & $\begin{array}{l}\text { Perfluorooctane sulfonamide } \\
\text { acetic acid }\end{array}$ & $2806-24-8$ & 0.5 & - \\
\hline & MeFOSAA & $\begin{array}{l}\text { N-Methyl-perfluorooctane } \\
\text { sulfonamido acetic acid }\end{array}$ & $2355-31-9$ & 0.05 & - \\
\hline & EtFOSAA & $\begin{array}{l}\text { N-ethyl perfluorooctane } \\
\text { sulfonamido acetic acid }\end{array}$ & 2991-50-6 & 0.05 & - \\
\hline $\begin{array}{l}\text { Fluorotelomer } \\
\text { phosphate }\end{array}$ & 6:2-diPAP & $\begin{array}{l}\text { 6:2 Fluorotelomer phosphate } \\
\text { diester }\end{array}$ & $57677-95-9$ & 0.5 & - \\
\hline
\end{tabular}




\begin{tabular}{|c|c|c|c|c|c|}
\hline \multirow[t]{2}{*}{ class } & \multirow[t]{2}{*}{ acronym } & \multirow[t]{2}{*}{ name } & \multirow[t]{2}{*}{ CAS } & \multicolumn{2}{|c|}{$\begin{array}{l}\text { LOQ } \\
\text { ( } \mu \mathrm{kg} \mathrm{kg}^{-1} \text { dry weight) }\end{array}$} \\
\hline & & & & target & dTOP \\
\hline \multirow[t]{2}{*}{ diesters (diPAP) } & 8:2-diPAP & $\begin{array}{l}\text { 8:2 Fluorotelomer phosphate } \\
\text { diester }\end{array}$ & $678-41-1$ & 0.5 & - \\
\hline & $\begin{array}{l}\text { 6:2/8:2- } \\
\text { diPAP }\end{array}$ & $\begin{array}{l}\text { 6:2/8:2 Fluorotelomer phosphate } \\
\text { diester }\end{array}$ & $943913-15-3$ & 0.5 & - \\
\hline \multirow{8}{*}{$\begin{array}{l}\text { Others } \\
\text { (replacements } \\
\text { and related } \\
\text { compounds) }\end{array}$} & ADONA & $\begin{array}{l}\text { 3H-perfluoro-3-[(3-methoxy- } \\
\text { propoxy)propanoic acid], } \\
\text { ammonium salt }\end{array}$ & $958445-44-8$ & 0.05 & - \\
\hline & $\begin{array}{l}9 \mathrm{Cl}- \\
\text { PF3ONS }\end{array}$ & $\begin{array}{l}\text { Potassium 9- } \\
\text { chlorohexadecafluoro-3- } \\
\text { oxanonane-1-sulfonat (main } \\
\text { compound of F53B) }\end{array}$ & $73606-19-6$ & 0.05 & - \\
\hline & $\begin{array}{l}\text { 11Cl- } \\
\text { PF3OUdS }\end{array}$ & $\begin{array}{l}\text { Potassium 11-chloroeicosafluoro- } \\
\text { 3-oxaundecane-1-sulfonate } \\
\text { (minor compound of F53B) }\end{array}$ & $83329-89-9$ & 0.5 & - \\
\hline & HFPO-DA & $\begin{array}{l}\text { GenX, 2,3,3,3-Tetrafluoro-2- } \\
\text { (heptafluoropropoxy)propanoic } \\
\text { acid }\end{array}$ & $62037-80-3$ & 0.5 & - \\
\hline & 7H-PFHpA & 7H-Dodecafluoroheptanoic acid & $1546-95-8$ & 0.05 & - \\
\hline & PFECHS & $\begin{array}{l}\text { Perfluoro-4- } \\
\text { ethylcyclohexanesulfonate }\end{array}$ & $646-83-3$ & 0.5 & - \\
\hline & PFMOPrA & $\begin{array}{l}\text { Perfluoro-3-methoxypropanoic } \\
\text { acid (oxidation product of } \\
\text { ADONA) }\end{array}$ & $377-73-1$ & 0.5 & 1.0 \\
\hline & 8:2 FTCA & 8:2-fluorotelomer carboxylic acid & $27854-31-5$ & 0.5 & - \\
\hline
\end{tabular}


QQ plot residuals

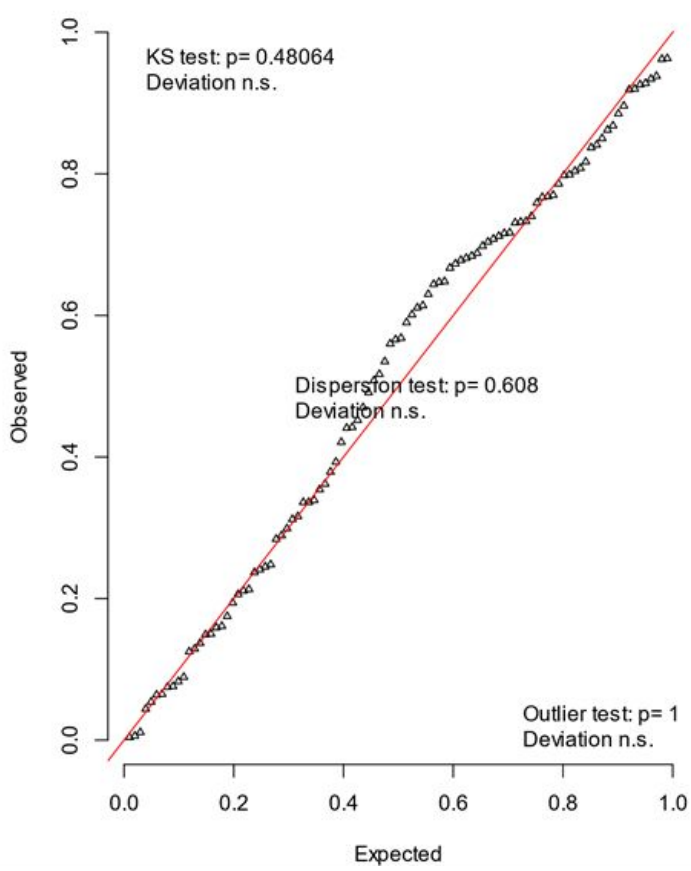

Residual vs predicted

No significant problems detected

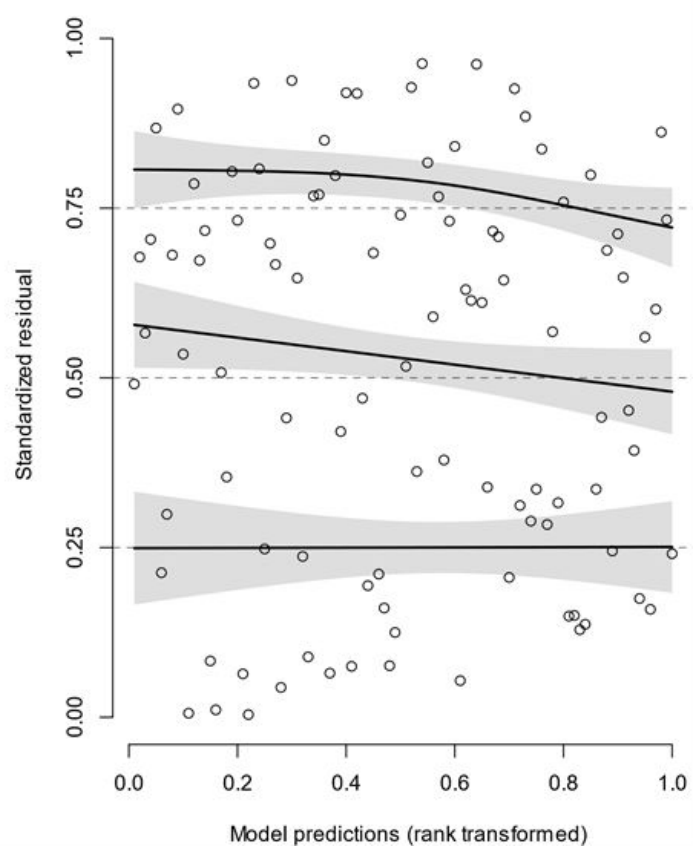

Figure S1: Verification of model assumptions for Gaussian GLM (identity link) on $\log _{\mathrm{e}}$ transformed $\sum_{13}$ PFCA concentrations measured by target analytics. Number of simulations $=1000$.
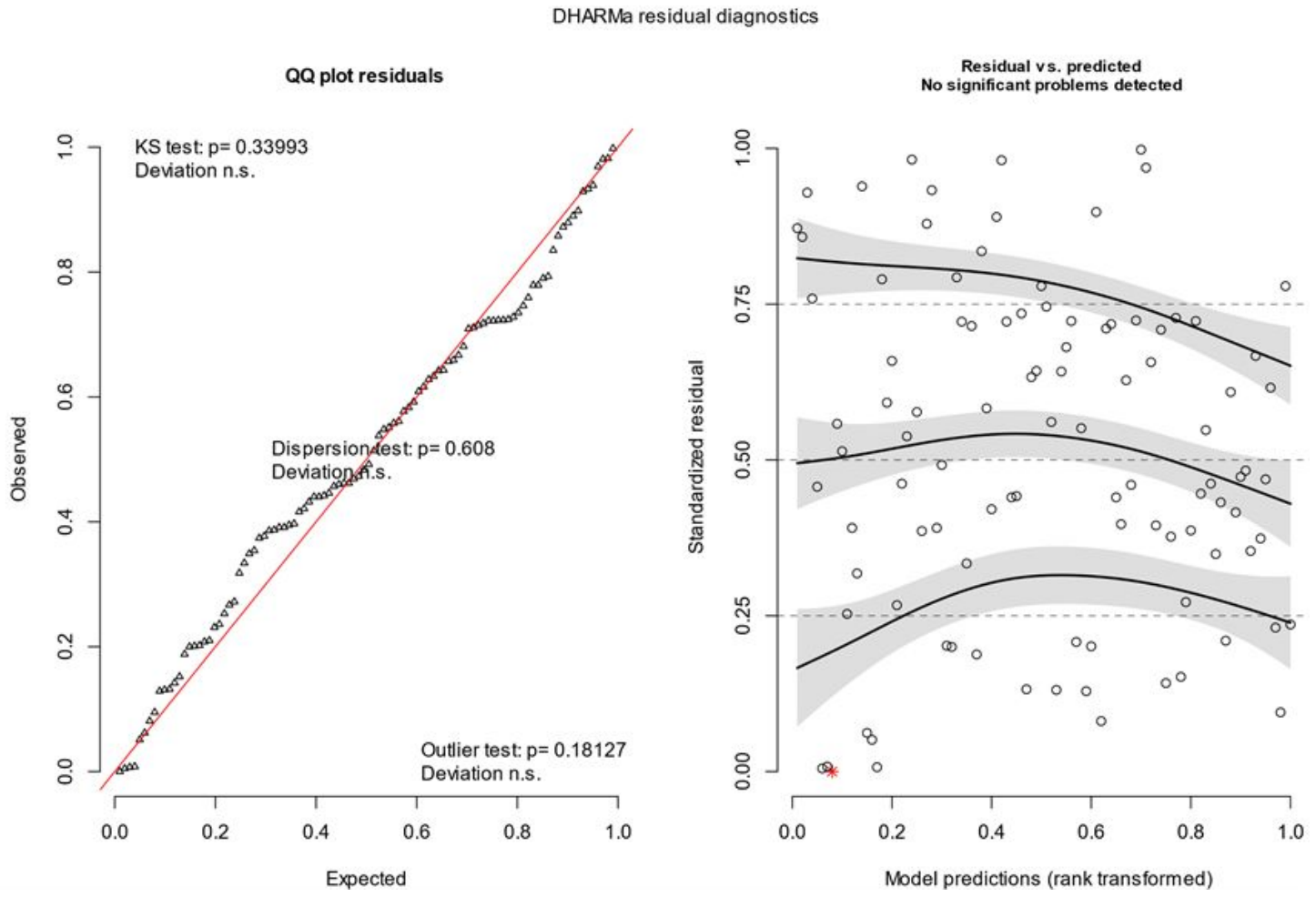

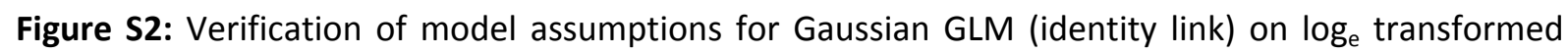
$\Sigma_{13}$ PFCA concentrations measured by dTOP assay. Number of simulations $=1000$. 


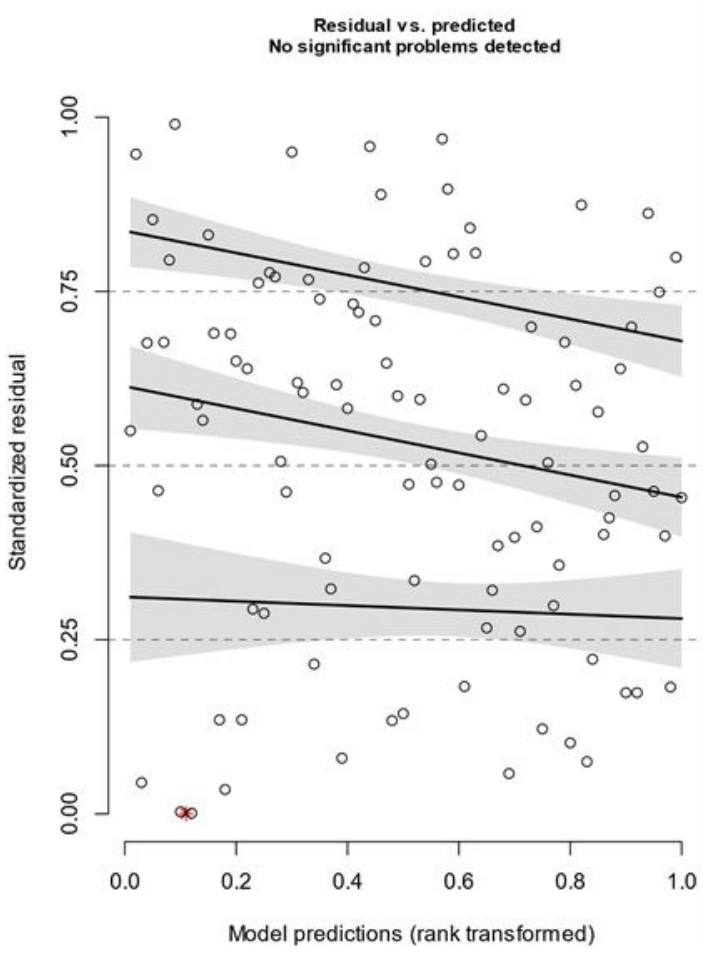

Figure S3: Verification of model assumptions for Gaussian GLM (identity link) on log transformed $\sum_{8}$ PFSA concentrations measured by target analytics. Number of simulations $=1000$.

Table S3: Estimates of the fixed effects on the $\log _{\mathrm{e}}$-concentrations of $\sum_{8} \mathrm{PFSA}_{\mathrm{dTOP}}$ excluding the outlier (E1 (Prossen) 2019). The reference category for river was set to Danube. Transformation in percent: (exp(estimate)-1)*100.

\begin{tabular}{|c|c|c|c|c|c|c|}
\hline \multicolumn{7}{|c|}{ dTOP } \\
\hline \multirow{3}{*}{} & & $\begin{array}{c}\text { Change in percent per } \\
\text { unit }\end{array}$ & Estimates & $\begin{array}{c}\text { Std. } \\
\text { Error }\end{array}$ & t value & $p$-value \\
\hline \multirow{2}{*}{ Year } & & -5.63 & -0.06 & 0.01 & -8.81 & $<0.001$ \\
\hline \multirow{2}{*}{ River } & Elbe & +48.5 & 0.40 & 0.10 & 4.00 & $<0.001$ \\
\cline { 2 - 8 } & Mulde & +186 & 1.05 & 0.13 & 7.95 & $<0.001$ \\
\cline { 2 - 8 } & Rhine & +74.7 & 0.56 & 0.10 & 5.36 & $<0.001$ \\
\cline { 2 - 8 } & Saale & +91.0 & 0.65 & 0.13 & 4.82 & $<0.001$ \\
\cline { 2 - 8 } & Saar & +30.7 & 0.27 & 0.11 & 2.34 & $<0.05$ \\
\hline TOC [\%] & & +27.0 & 0.24 & 0.02 & 11.42 & $<0.001$ \\
\hline
\end{tabular}


QQ plot residuals

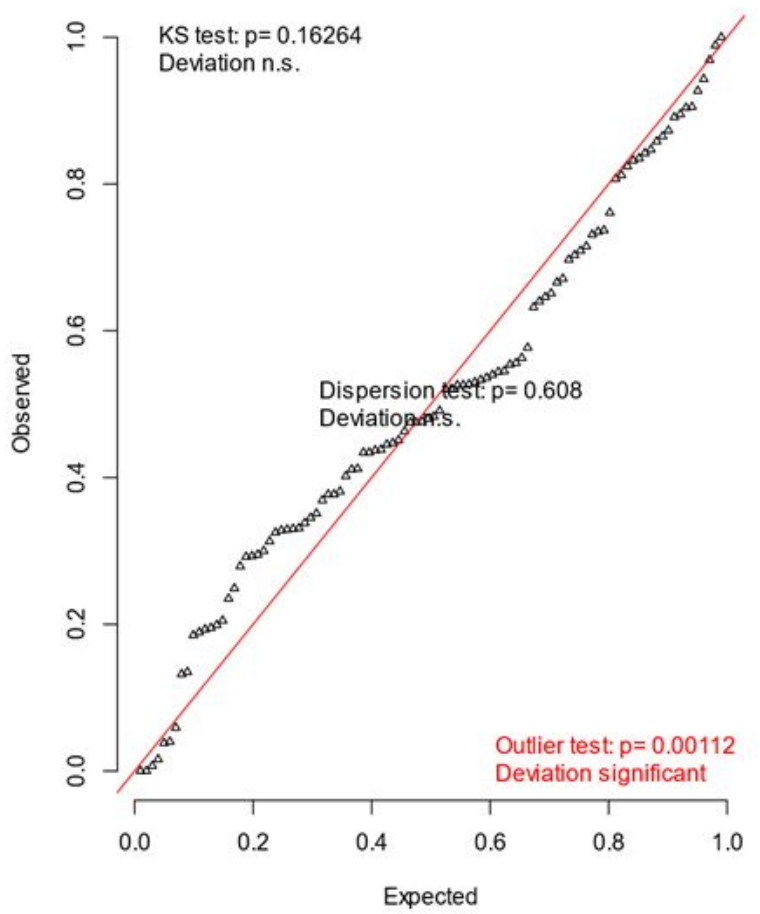

Residual vs. predicted No significant problems detected

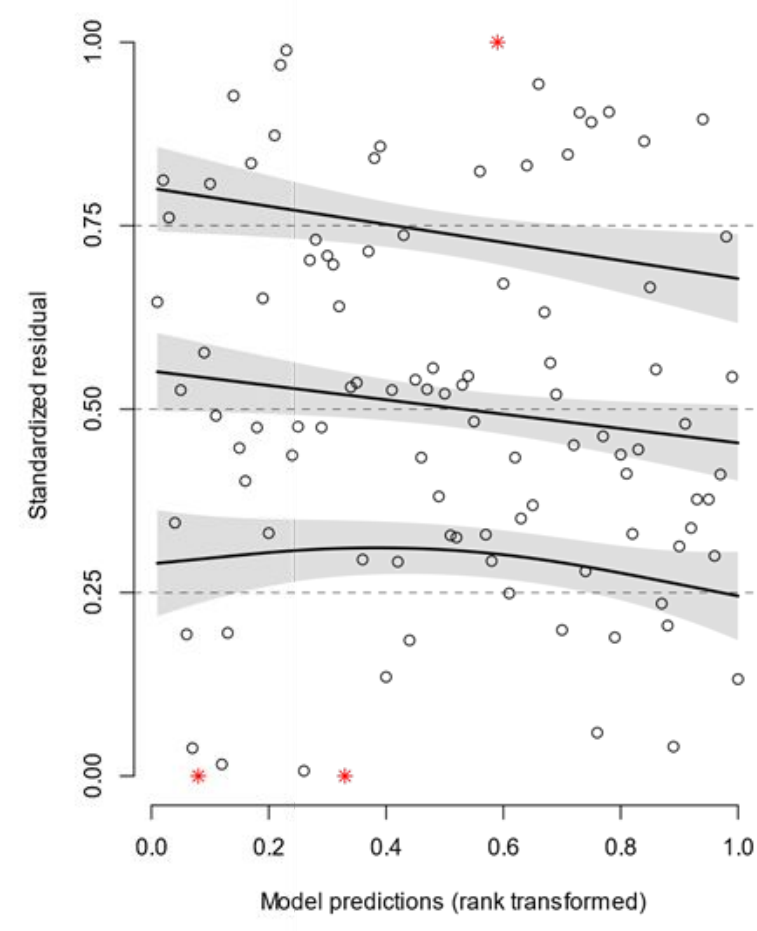

Model predictions (rank transformed)
QQ plot residuals

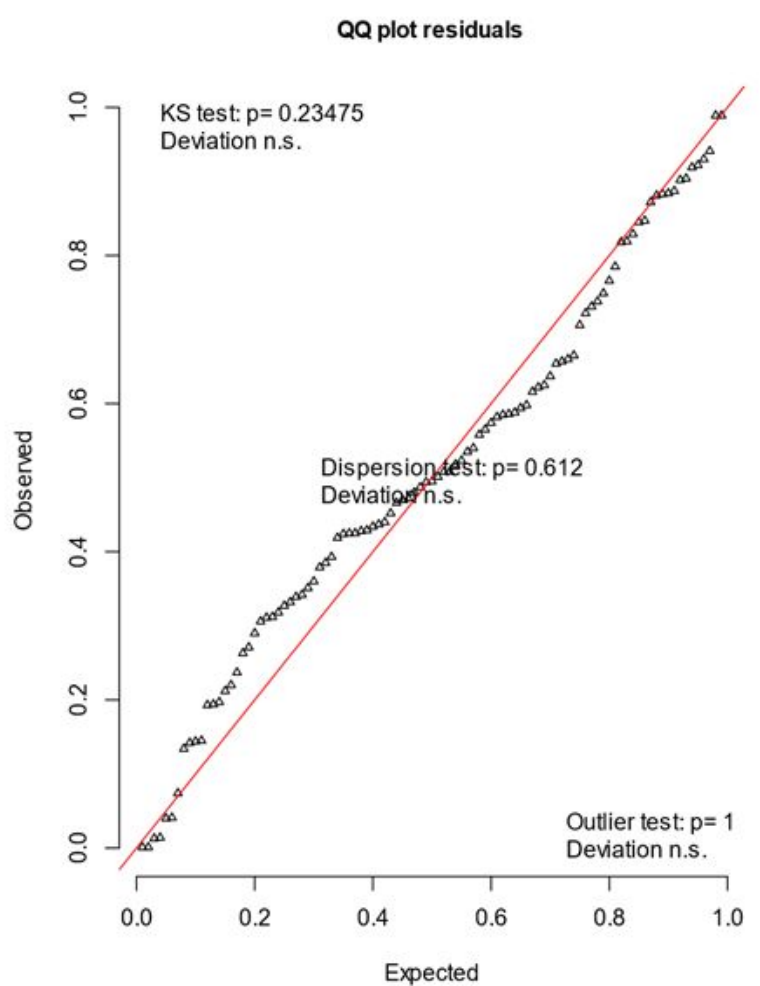

DHARMa residual diagnostics

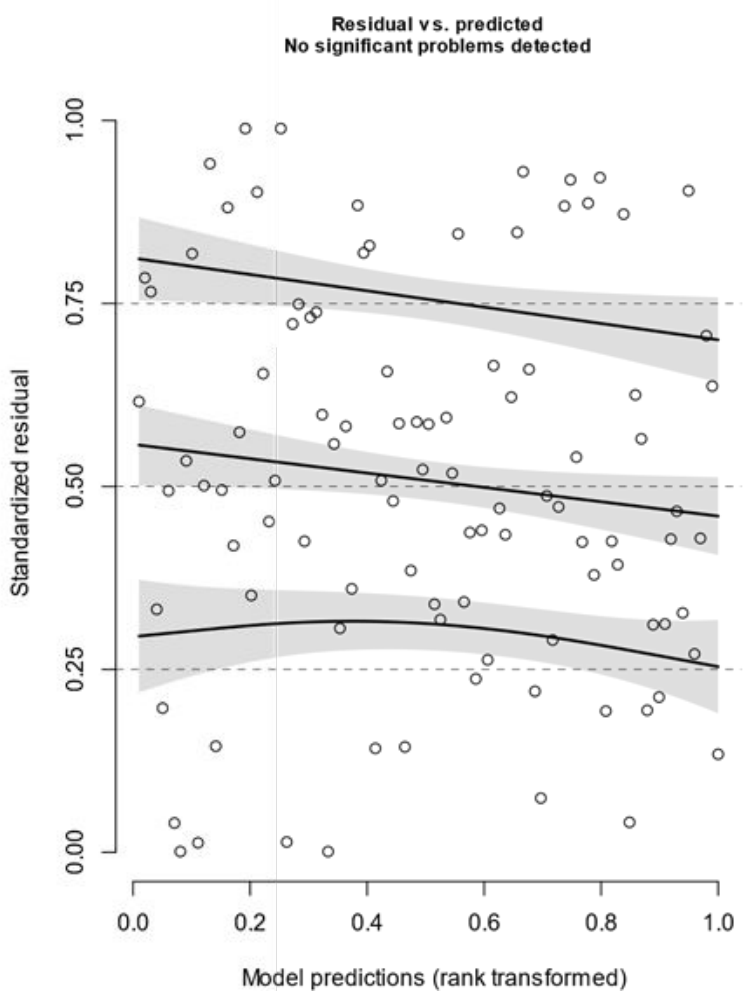

Figure S4: Verification of model assumptions for Gaussian GLM (identity link) on log transformed $\Sigma_{8}$ PFSA concentrations measured by dTOP assay with (A) and without (B) the outlier Prossen 2019 (Elbe). Number of simulations $=1000$. 
QQ plot residuals

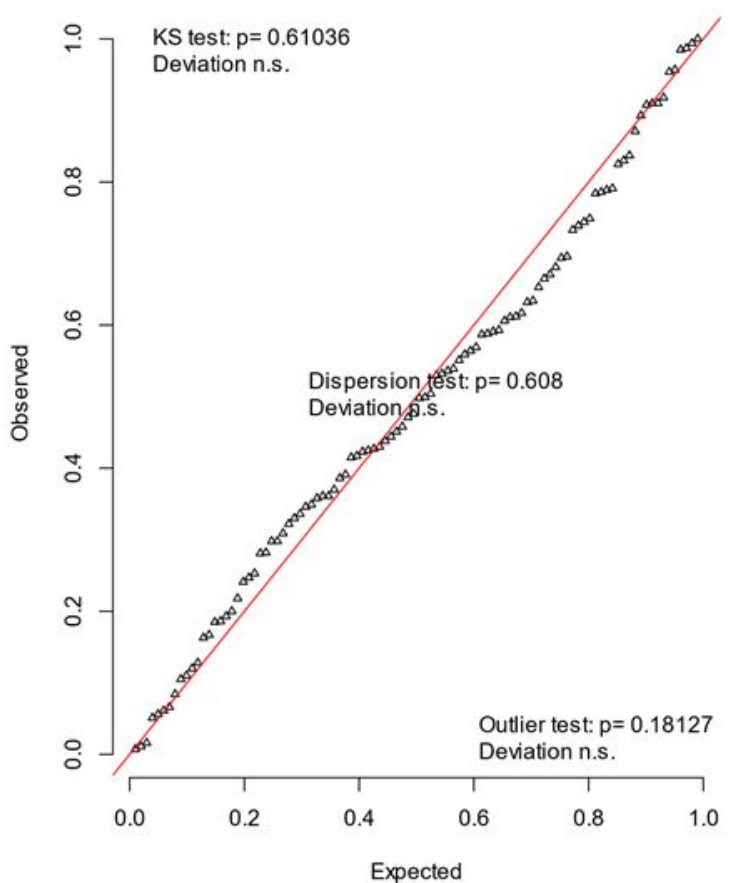

Residual vs. predicted No significant problems detected

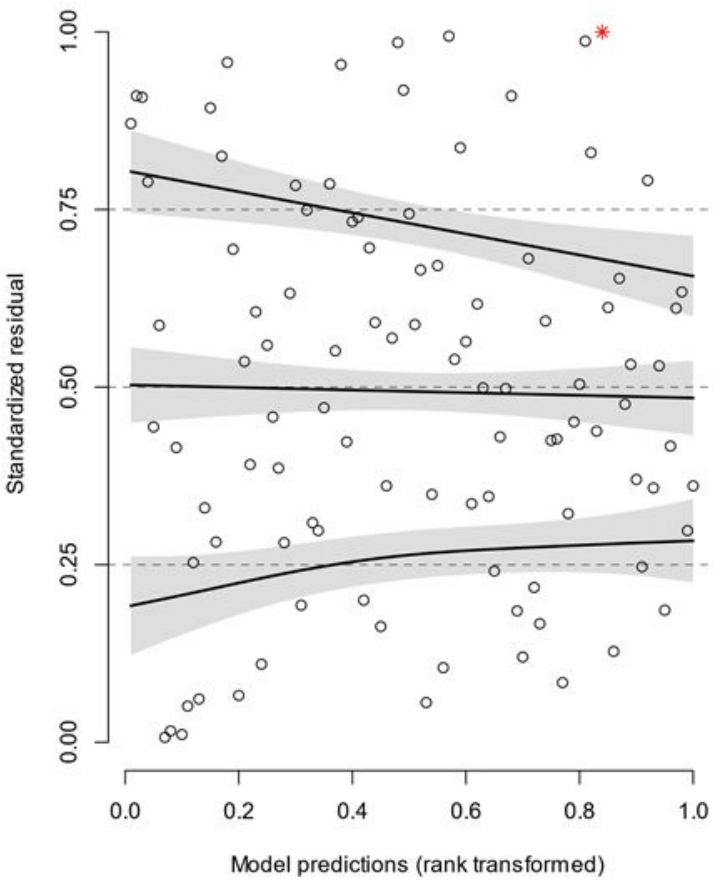

Figure S5: Verification of model assumptions for Gaussian GLM (identity link) on $\log _{\mathrm{e}}$ transformed $\Sigma \mathrm{C}_{4^{-}}$ $\mathrm{C}_{7} \mathrm{PFCA}$ concentrations measured by dTOP assay. Number of simulations $=1000$.

DHARMa residual diagnostics

QQ plot residuals

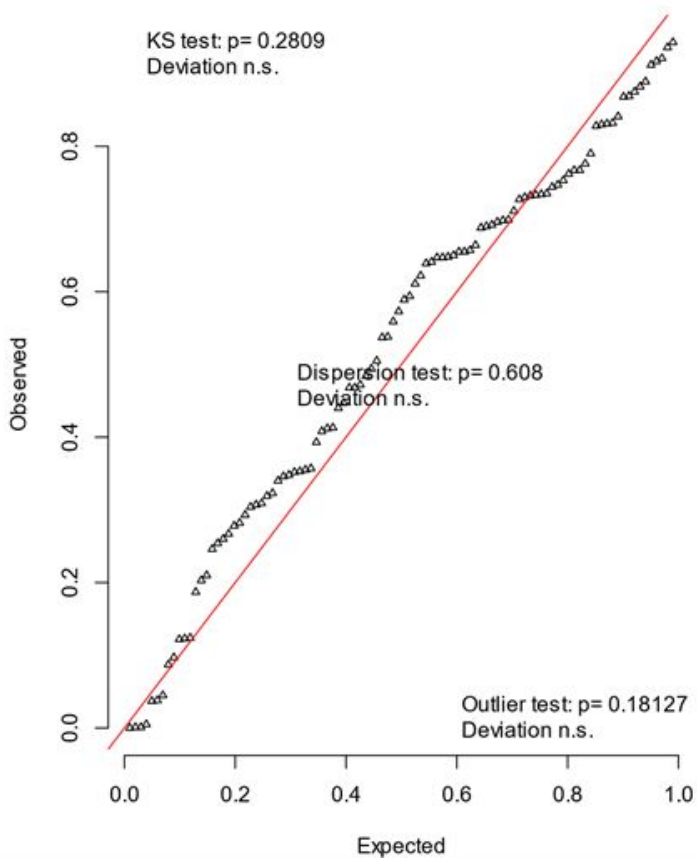
Residual vs. predicted
No significant problems detected

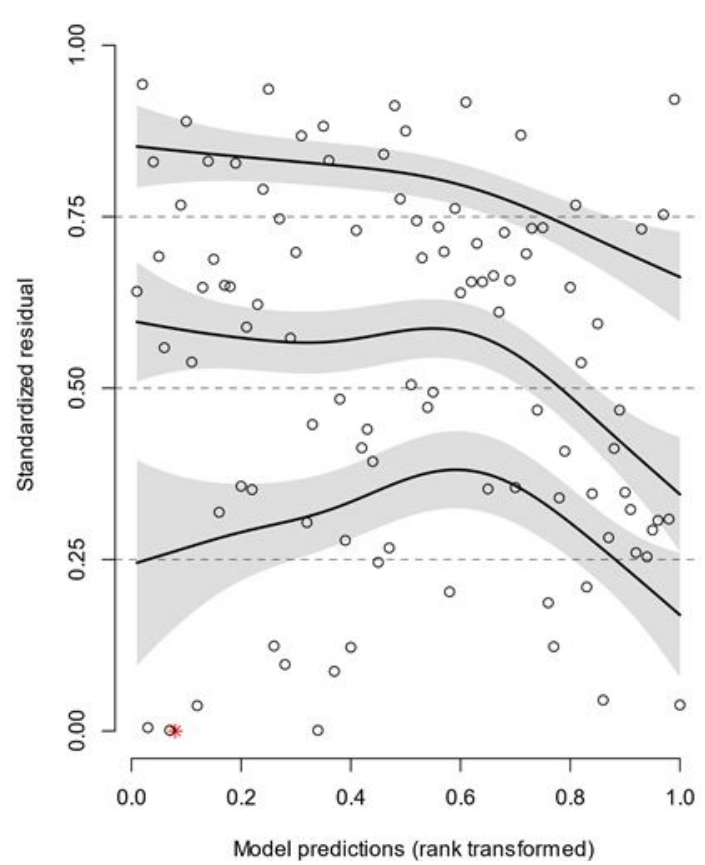

Figure S6: Verification of model assumptions for Gaussian GLM (identity link) on log $\log _{\mathrm{e}}$ transformed $\sum \mathrm{C}_{8^{-}}$ $\mathrm{C}_{18}$ PFCA concentrations measured by dTOP assay. Number of simulations $=1000$. 


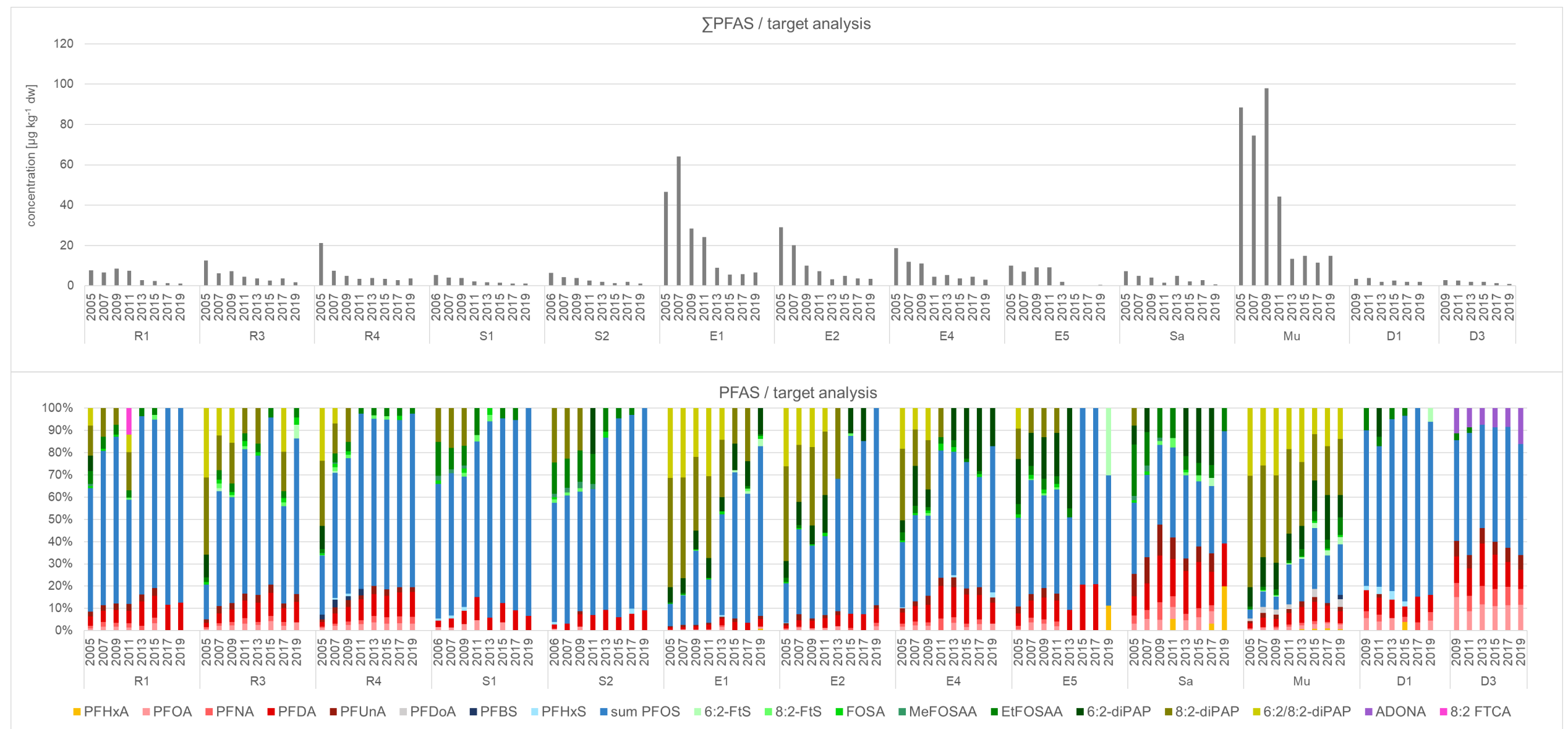

Figure S7: Target analysis: PFAS concentrations ( $\mu \mathrm{g} \mathrm{kg}^{-1} \mathrm{dry}$ weight (dw), upper panel) and patterns of PFAS (\% per compound, lower panel) in suspended particulate matter from the sampling sites of the German Environmental Specimen Bank.

R1: Rhine-Weil, R3: Rhine-Koblenz; R4: Rhine-Bimmen; S1: Saar-Guedingen: S2: Saar-Rehlingen; E1: Elbe-Prossen; E2: Elbe-Zehren; E4: Elbe-Cumlosen; E5: ElbeBlankenese; Sa: Saale-Wettin; Mu: Mulde-Dessau; D1: Danube-Ulm; D3: Danube-Jochenstein. LOQ: $0.05-0.5 \mu \mathrm{kg}^{-1} \mathrm{dw}$. 


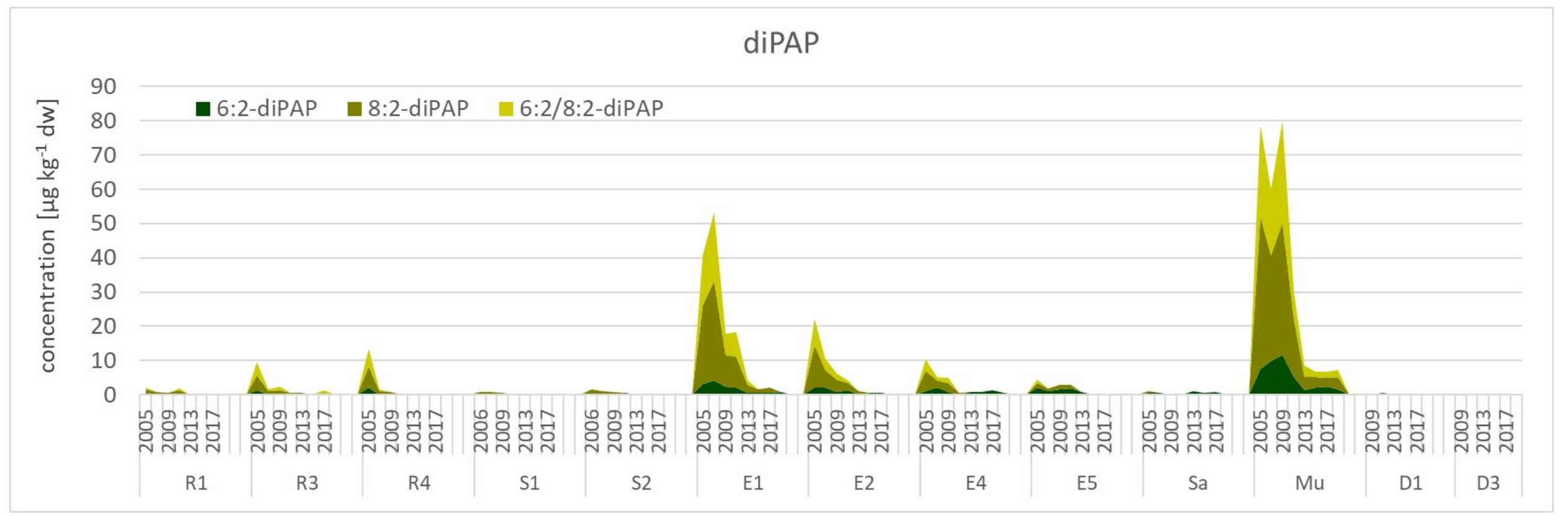

Figure S8: Target analysis: Concentrations ( $\mu \mathrm{g} \mathrm{kg}^{-1} \mathrm{dry}$ weight $(\mathrm{dw})$ ) of diPAP in suspended particulate matter from the sampling sites of the German Environmental Specimen Bank.

R1: Rhine-Weil, R3: Rhine-Koblenz; R4: Rhine-Bimmen; S1: Saar-Guedingen: S2: Saar-Rehlingen; E1: Elbe-Prossen; E2: Elbe-Zehren; E4: Elbe-Cumlosen; E5: ElbeBlankenese; Sa: Saale-Wettin; Mu: Mulde-Dessau; D1: Danube-Ulm; D3: Danube-Jochenstein. LOQ: $0.5 \mu \mathrm{g} \mathrm{kg}^{-1} \mathrm{dw}$. 


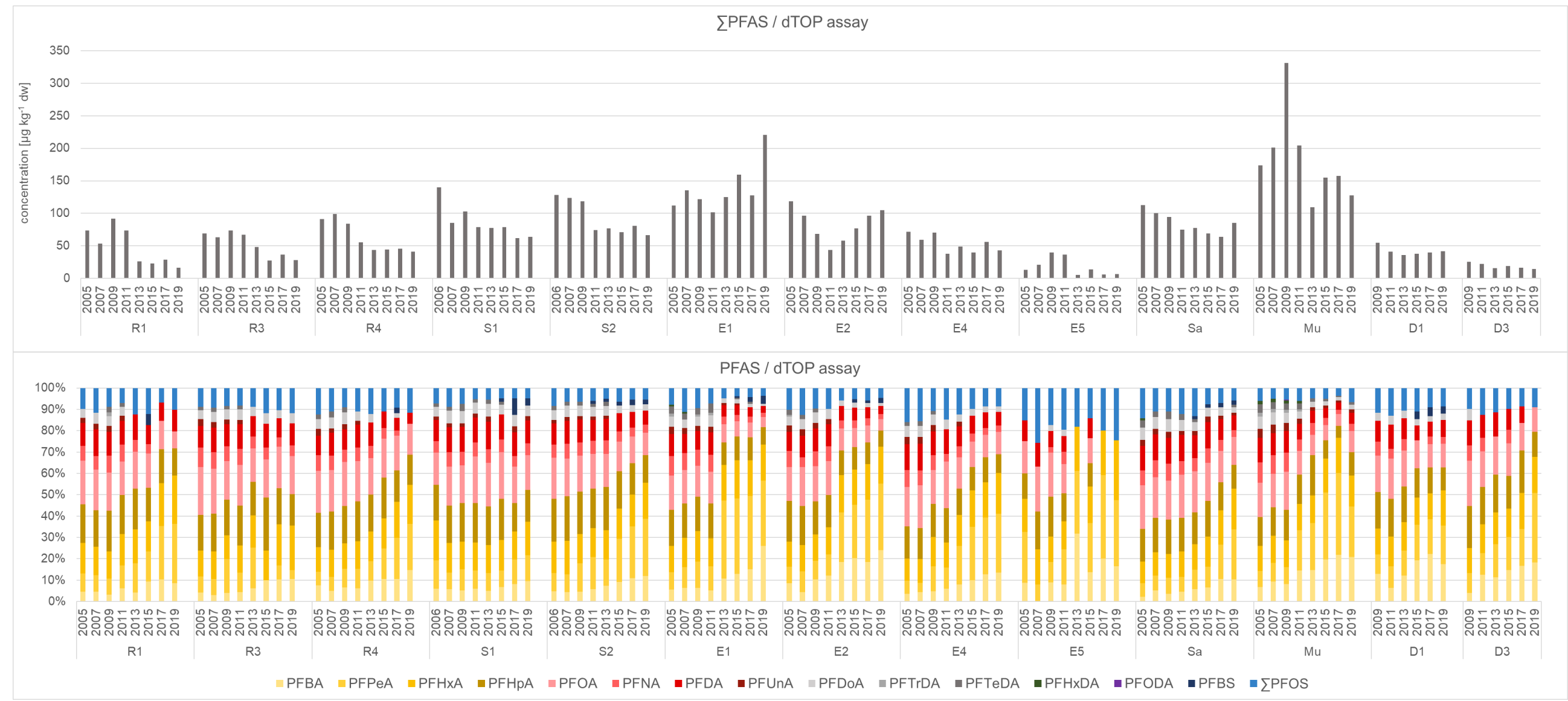

Figure S9: dTOP assay: PFAS concentrations ( $\mu \mathrm{kg}^{-1} \mathrm{dry}$ weight ( $\mathrm{dw}$ ), upper panel) and patterns of PFAS (\% per compound, lower panel) in suspended particulate matter from the sampling sites of the German Environmental Specimen Bank.

R1: Rhine-Weil, R3: Rhine-Koblenz; R4: Rhine-Bimmen; S1: Saar-Guedingen: S2: Saar-Rehlingen; E1: Elbe-Prossen; E2: Elbe-Zehren; E4: Elbe-Cumlosen; E5: ElbeBlankenese; Sa: Saale-Wettin; Mu: Mulde-Dessau; D1: Danube-Ulm; D3: Danube-Jochenstein. LOQ: $1.0 \mu \mathrm{g} \mathrm{kg}^{-1} \mathrm{dw}$. 

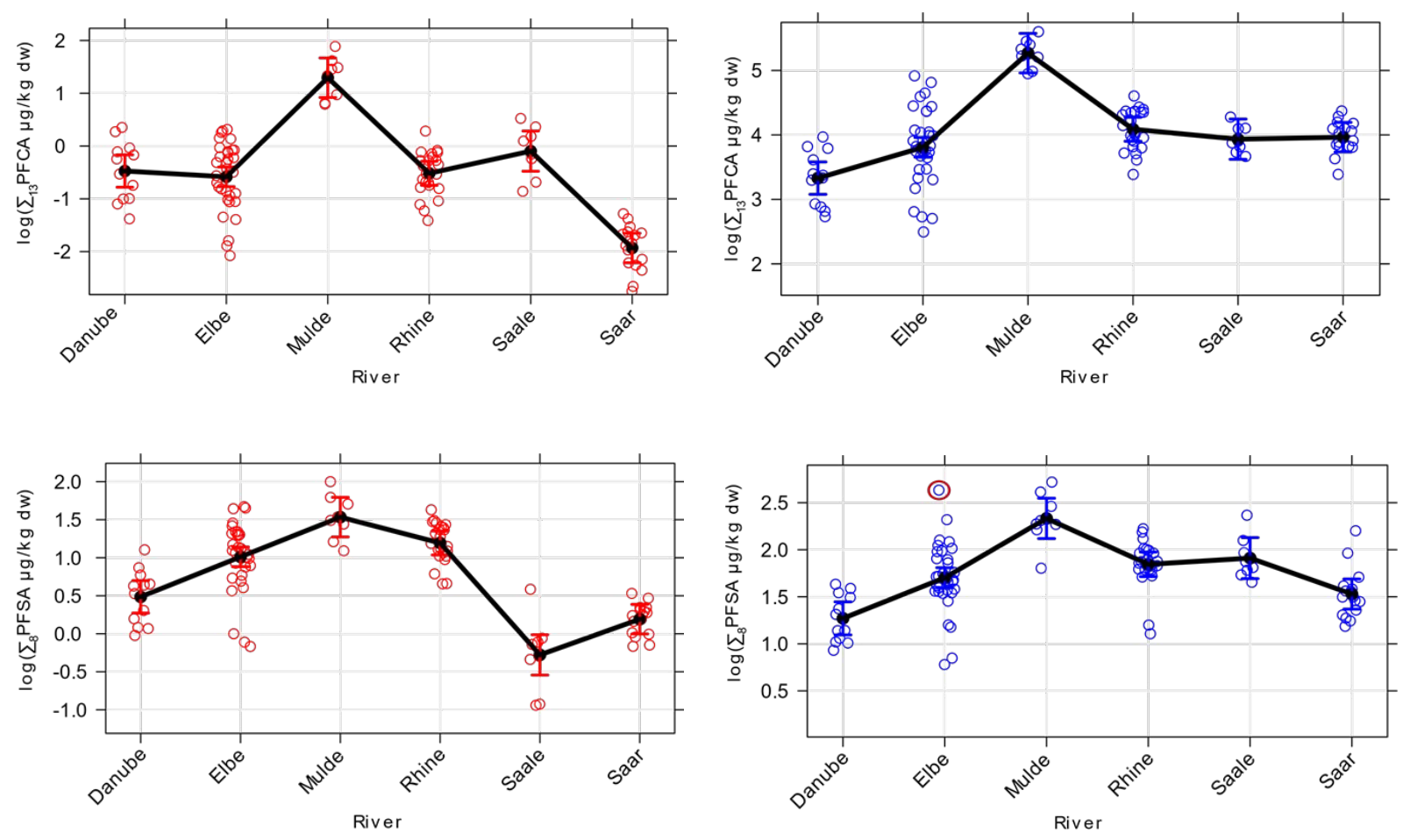

Figure S10: Predictor effect plots with partial regression line, partial residuals (dots) and error bars showing the effect of 'river' on $\log _{\mathrm{e}}$ transformed $\Sigma_{13} \mathrm{PFCA}$ and $\Sigma_{8} \mathrm{PFSA}$ concentrations ( $\mu \mathrm{g} \mathrm{kg}^{-1} \mathrm{dry}$ weight $\mathrm{dw}$ ) in suspended particulate matter from German rivers. Additional fixed effects in the GLM comprised 'year' (Figure 3) and 'total organic carbon' (Figure S13) to account for variations introduced by both effects. Red: data from target analysis (LOQ: $0.05-0.5 \mu \mathrm{g} \mathrm{kg}^{-1}$ ); blue: data from dTOP assay (LOQ: $1.0 \mu \mathrm{g} \mathrm{kg}{ }^{-1} \mathrm{dw}$ ). The red circle in the lower right panel marks an outlier (sampling site E1 (Prossen), 2019). 
Table S4: Results of the generalized linear modelling of short- and long-chain PFCA $\left(\sum \mathrm{C}_{4}-\mathrm{C}_{7}\right.$ and $\sum \mathrm{C}_{8^{-}}$ $\mathrm{C}_{18}$ ) concentrations in suspended particulate matter from German rivers determined by dTOP assay. The reference category for river was set to Danube. Transformation in percent: (exp(estimate)-1)*100.

\begin{tabular}{|c|c|c|c|c|c|c|}
\hline Fixed factors & & $\begin{array}{l}\text { Change in } \\
\text { percent per unit }\end{array}$ & Estimates & $\begin{array}{l}\text { Std. } \\
\text { Error }\end{array}$ & t value & $p$-value \\
\hline \multicolumn{7}{|c|}{$\log _{\mathrm{e}}\left(\sum \mathrm{C}_{4}-\mathrm{C}_{7}\right.$ PFCA $\mu \mathrm{gg}^{-1}$ dry weight $)$} \\
\hline Year & & -0.64 & -0.01 & 0.01 & -0.69 & 0.49 \\
\hline \multirow[t]{5}{*}{ River } & Elbe & +72.2 & 0.54 & 0.14 & 3.79 & $<0.001$ \\
\hline & Mulde & +596 & 1.94 & 0.19 & 10.05 & $<0.001$ \\
\hline & Rhine & +94.1 & 0.66 & 0.15 & 4.37 & $<0.001$ \\
\hline & Saale & +50.8 & 0.41 & 0.20 & 2.09 & $<0.05$ \\
\hline & Saar & +74.8 & 0.56 & 0.17 & 3.35 & 0.001 \\
\hline TOC [\%] & & +36.7 & 0.31 & 0.03 & 10.35 & $<0.001$ \\
\hline \multicolumn{7}{|c|}{$\log _{\mathrm{e}}\left(\sum \mathrm{C}_{8}-\mathrm{C}_{18} \text { PFCA } \mu \mathrm{gg}^{-1} \text { dry weight }\right)^{*}$} \\
\hline Year & & -9.65 & -0.10 & 0.01 & -9.57 & $<0.001$ \\
\hline \multirow[t]{5}{*}{ River } & Elbe & +32.0 & 0.28 & 0.16 & 1.73 & 0.09 \\
\hline & Mulde & +462 & 1.73 & 0.22 & 8.00 & $<0.001$ \\
\hline & Rhine & +127 & 0.82 & 0.17 & 4.83 & $<0.001$ \\
\hline & Saale & +126 & 0.81 & 0.22 & 3.71 & $<0.001$ \\
\hline & Saar & +108 & 0.73 & 0.19 & 3.93 & $<0.001$ \\
\hline TOC [\%] & & +36.6 & 0.31 & 0.03 & 9.23 & $<0.001$ \\
\hline
\end{tabular}

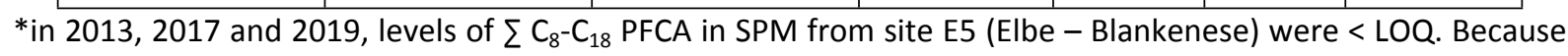
values $<\mathrm{LOQ}$ are set as zero in the calculation, a $\log _{\mathrm{e}}$-shift transformation had to be performed. 

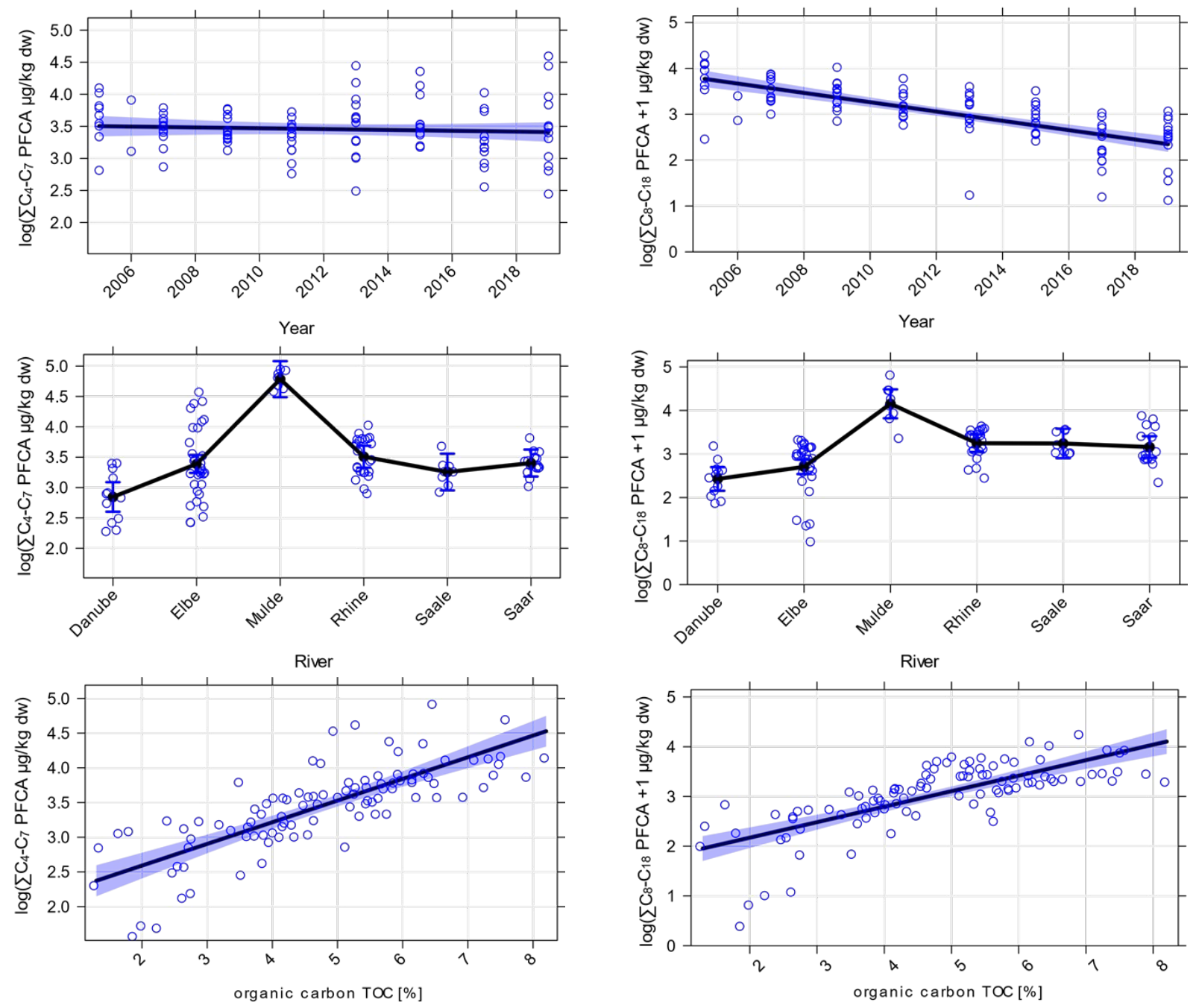

Figure S11: Predictor effect plots (with partial regression line, partial residuals (dots) and 95\% confidence intervals or error bars) showing the effect of 'year' (upper panels), 'river' (middle panels), and organic carbon (TOC) content (lower panels) on $\log _{e}$ transformed concentrations of short- $\left(\sum \mathrm{C}_{4}-\mathrm{C}_{7}\right.$, left side) and long-chain ( $\sum \mathrm{C}_{8}-\mathrm{C}_{18}$, right side) PFCA concentrations ( $\mu \mathrm{g} \mathrm{kg}^{-1} \mathrm{dry}$ weight $\mathrm{dw}$ ) in suspended particulate matter from German rivers determined by dTOP assay. LOQ: $1.0 \mu \mathrm{g} \mathrm{kg}^{-1} \mathrm{dw}$. 
Table S5: Physicochemical characteristics of suspended particulate matter collected at the sampling sites of the German environmental specimen bank during the study period.

\begin{tabular}{|l|l|l|l|l|l|l|l|}
\hline Sampling site & acronym & period & pH & TOC [\%] & Sand [\%] & Silt [\%] & Clay [\%] \\
\hline Rhine / Weil & R1 & $2005-2019$ & $6.56-6.96$ & $2.46-4.55$ & $3.1-18.0$ & $56.2-77.1$ & $14.6-75.7$ \\
\hline Rhine / Koblenz & R3 & $2005-2019$ & $7.02-7.36$ & $2.38-3.94$ & $4.3-7.9$ & $61.8-82.5$ & $11.1-32.2$ \\
\hline Rhine / Bimmen & R4 & $2005-2019$ & $7.14-7.37$ & $3.67-5.58$ & $2.7-17.0$ & $65.7-74.1$ & $17.3-26.5$ \\
\hline Saar / Guedingen & S1 & $2006-2019$ & $6.76-7.31$ & $4.63-6.39$ & $5.9-28.5$ & $46.2-64.1$ & $25.4-36.4$ \\
\hline Saar / Rehlingen & S2 & $2006-2019$ & $6.64-7.20$ & $5.17-8.17$ & $1.6-18.0$ & $53.7-62.7$ & $28.4-40.8$ \\
\hline Elbe / Prossen & E1 & $2005-2019$ & $6.53-6.95$ & $5.27-7.57$ & $5.8-11.2$ & $56.9-77.4$ & $16.3-34.9$ \\
\hline Elbe / Zehren & E2 & $2005-2019$ & $6.42-7.14$ & $3.48-5.79$ & $1.9-10.9$ & $64.9-80.4$ & $17.1-26.2$ \\
\hline Elbe / Cumlosen & E4 & $2005-2019$ & $6.86-7.30$ & $4.14-7.24$ & $3.7-20.9$ & $74.3-88.1$ & $4.8-21.8$ \\
\hline Elbe / Blankenese & E5 & $2005-2019$ & $7.05-7.47$ & $1.26-4.33$ & $9.1-26.9$ & $60.3-82.2$ & $5.1-16.4$ \\
\hline Saale/ Wettin & Sa & $2005-2019$ & $7.06-7.38$ & $5.13-6.48$ & $0.9-2.5$ & $62.7-83.9$ & $14.0-35.4$ \\
\hline Mulde / Dessau & Mu & $2005-2019$ & $6.44-6.96$ & $2.71-5.62$ & $6.6-21.9$ & $60.1-79.6$ & $10.1-20.9$ \\
\hline Danube / Ulm & D1 & $2009-2019$ & $7.01-7.16$ & $5.67-7.89$ & $5.1-8.9$ & $62.4-71.3$ & $23.1-30.2$ \\
\hline Danube / Jochenstein & D3 & $2009-2019$ & $7.05-7.25$ & $1.33-3.72$ & $9.7-19.7$ & $63.4-73.4$ & $12.4-19.2$ \\
\hline
\end{tabular}




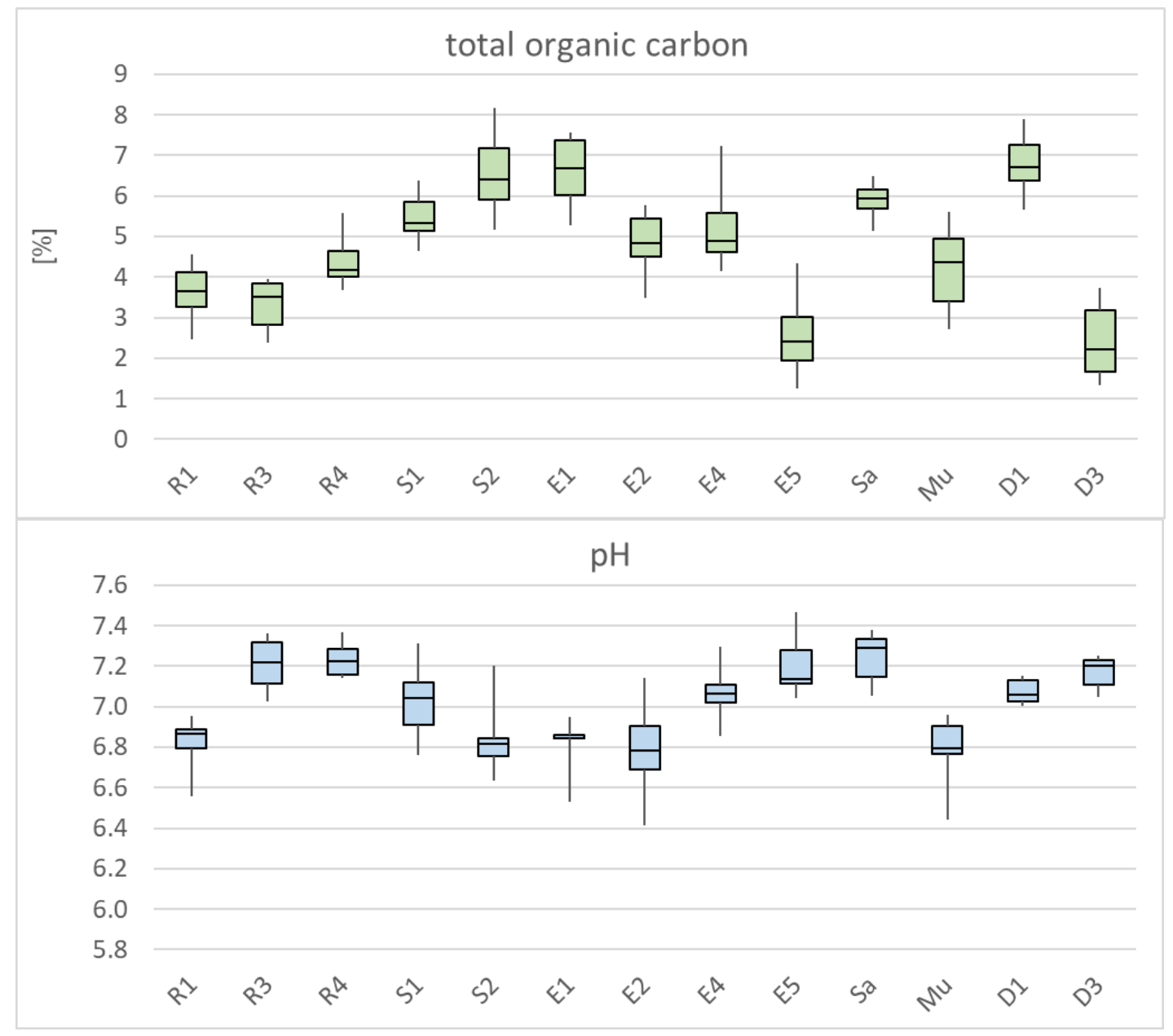

Figure S12: Range of total organic carbon (TOC) contents and $\mathrm{pH}$-values in suspended particulate matter sampled between 2005 and 2019 in German rivers. The lower and upper ends of the boxes mark the 25th and 75th percentiles of the data, the end of the whiskers show the maximum and minimum values. Data per sampling site: $n=7$; for $D 1$ and $D 3: n=5$.

R1: Rhine-Weil, R3: Rhine-Koblenz; R4: Rhine-Bimmen; S1: Saar-Guedingen: S2: Saar-Rehlingen; E1: Elbe-Prossen; E2: Elbe-Zehren; E4: Elbe-Cumlosen; E5: Elbe-Blankenese; Sa: Saale-Wettin; Mu: MuldeDessau; D1: Danube-Ulm; D3: Danube-Jochenstein. 

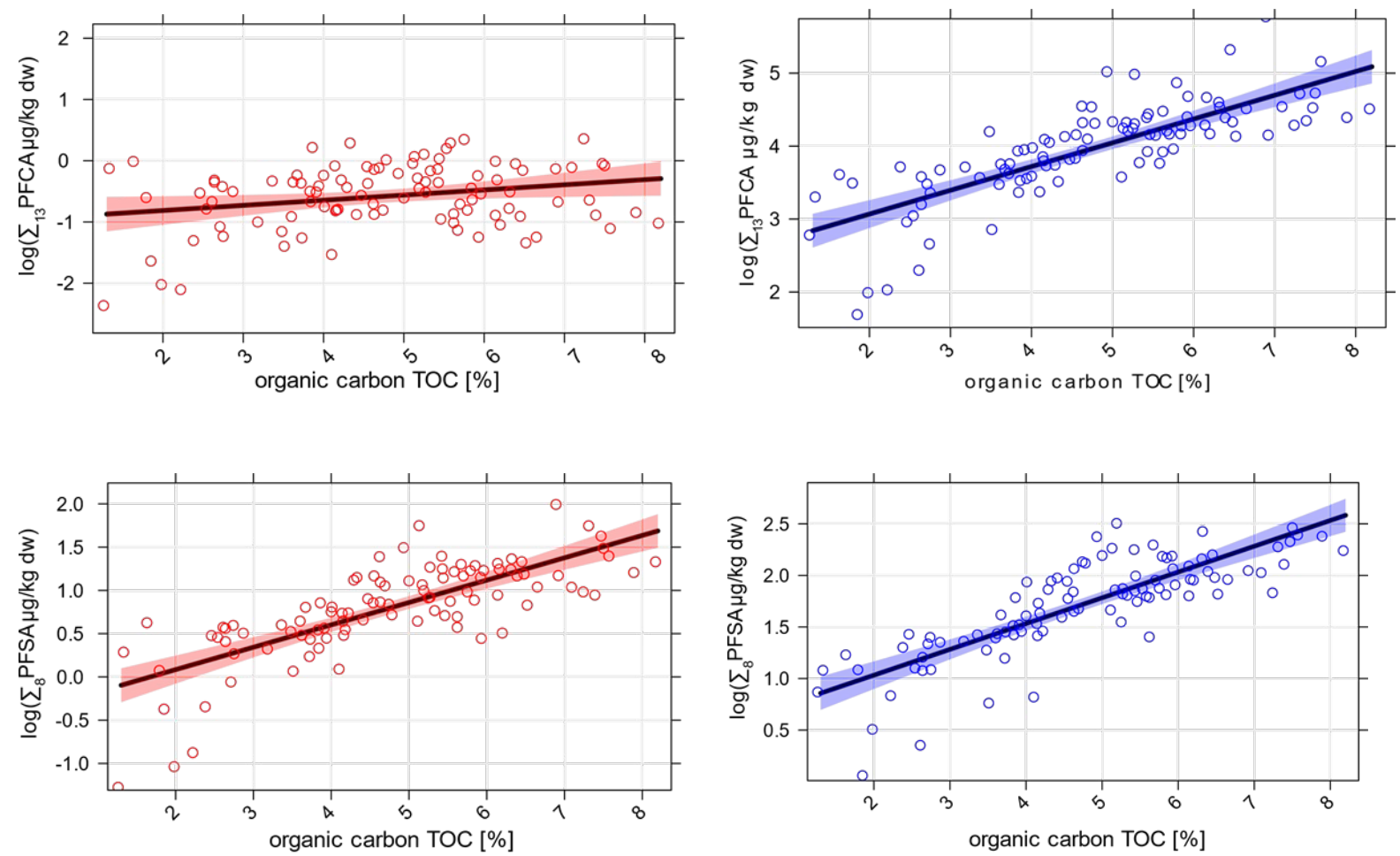

Figure S13: Predictor effect plots with partial regression line, partial residuals (dots) and $95 \%$ confidence intervals showing the effect of total organic carbon (TOC) content on $\log _{\mathrm{e}}$ transformed $\Sigma_{13}$ PFCA and $\sum_{8}$ PFSA concentrations ( $\mu \mathrm{kg}^{-1}$ dry weight $(\mathrm{dw})$ ) in suspended particulate matter from German rivers. Additional fixed effects in the GLM comprised 'year' (Figure 3) and 'river' (Figure S10) to account for variations introduced by both effects. Red: data from target analysis (LOQ: $0.05-0.5 \mu \mathrm{g}$ $\mathrm{kg}^{-1}$ ); blue: data from dTOP assay (LOQ: $1.0 \mu \mathrm{kg}^{-1} \mathrm{dw}$ ). 
Table S6: Calculated annual PFAS loads $\left(\mathrm{kg} \mathrm{a}^{-1}\right)$ of suspended particulate matter collected at the sampling sites of the German environmental specimen bank in in the first year of the study period and in 2017 and 2019. Calculations based on PFAS concentrations determined by target analysis (LOQ: $0.05-0.5 \mu \mathrm{g} \mathrm{kg}{ }^{-1} \mathrm{dry}$ weight (dw)) and dTOP assay (LOQ: $1.0 \mu \mathrm{g} \mathrm{kg}^{-1} \mathrm{dw}$ ) and on publicly available data on discharge and SPM concentration, e.g., from the International Commissions for the Protection of Rhine (ICPR), Elbe River (ICPER) and Danube River (IPCDR).

\begin{tabular}{|c|c|c|c|c|c|c|c|c|c|c|c|c|c|c|c|}
\hline \multirow[t]{2}{*}{ river } & \multirow[t]{2}{*}{ site } & \multirow[t]{2}{*}{ location } & \multirow[t]{2}{*}{ year } & \multirow{2}{*}{$\begin{array}{c}\text { Water } \\
\text { discharge } \\
{\left[\mathrm{m}^{3} / \mathrm{s}\right]}\end{array}$} & \multirow{2}{*}{$\begin{array}{l}\text { SPM } \\
\text { conc. } \\
{\left[\mathrm{g} / \mathrm{m}^{3}\right]}\end{array}$} & \multicolumn{5}{|c|}{ Data from target analysis $\left[\mathrm{kg} \mathrm{a}^{-1}\right]$} & \multicolumn{5}{|c|}{ Data from dTOP assay $\left[\mathrm{kg} \mathrm{a}^{-1}\right]$} \\
\hline & & & & & & $\sum$ PFCA & $\sum$ PFSA & $\begin{array}{l}\text { ¿Sulfon } \\
\text {-amides }\end{array}$ & $\sum$ diPAP & $\begin{array}{l}\text { ¿PFAS } \\
\text { Target }\end{array}$ & $\sum$ PFCA & $\sum$ PFSA & $\begin{array}{l}\text { ¿PFAS } \\
\text { dTOP }\end{array}$ & $\begin{array}{l}\sum \mathrm{C}_{4}-\mathrm{C}_{7} \\
\text { PFCA }\end{array}$ & $\begin{array}{c}\sum \mathrm{C}_{8}-\mathrm{C}_{18} \\
\text { PFCA }\end{array}$ \\
\hline \multirow[t]{9}{*}{ Rhine } & \multirow[t]{3}{*}{$\mathrm{R} 1$} & \multirow[t]{3}{*}{ Weil } & 2005 & 922 & 9.9 & 0.188 & 1.24 & 0.172 & 0.632 & 2.23 & 19.1 & 2.07 & 21.2 & 9.66 & 9.48 \\
\hline & & & 2017 & 911 & 8.2 & 0.034 & 0.255 & $<\mathrm{LOQ}$ & $<\mathrm{LOQ}$ & 0.289 & 6.31 & 0.467 & 6.77 & 4.83 & 1.48 \\
\hline & & & 2019 & 950 & 11.5 & 0.044 & 0.306 & $<\mathrm{LOQ}$ & $<\mathrm{LOQ}$ & 0.350 & 5.06 & 0.579 & 5.64 & 4.05 & 1.01 \\
\hline & \multirow[t]{3}{*}{ R3 } & \multirow[t]{3}{*}{ Koblenz } & 2005 & 1515 & 22.9 & 0.679 & 2.14 & 0.456 & 10.4 & 13.7 & 68.7 & 6.69 & 75.4 & 30.5 & 38.2 \\
\hline & & & 2017 & 1414 & 13.4 & 0.259 & 0.929 & 0.106 & 0.793 & 2.124 & 19.4 & 2.26 & 21.7 & 11.5 & 7.92 \\
\hline & & & 2019 & 1538 & 14.9 & 0.198 & 0.847 & 0.090 & $<\mathrm{LOQ}$ & 1.21 & 17.8 & 2.37 & 20.2 & 10.2 & 7.68 \\
\hline & \multirow[t]{3}{*}{ R4 } & \multirow[t]{3}{*}{ Bimmen } & 2005 & 1917 & 38.4 & 2.49 & 14.1 & 1.39 & 31.1 & 49.1 & 185 & 26.3 & 211 & 87.9 & 97.1 \\
\hline & & & 2017 & 1782 & 15.0 & 0.467 & 1.803 & 0.127 & $<\mathrm{LOQ}$ & 2.40 & 34.0 & 4.51 & 38.5 & 23.6 & 10.4 \\
\hline & & & 2019 & 1943 & 17.8 & 0.760 & 3.04 & 0.092 & $<\mathrm{LOQ}$ & 3.89 & 39.4 & 5.12 & 44.5 & 30.6 & 8.78 \\
\hline \multirow[t]{6}{*}{ Saar } & \multirow[t]{3}{*}{$\mathrm{S} 1$} & \multirow[t]{3}{*}{ Guedingen } & 2006 & 24.0 & 15.2 & 0.003 & 0.037 & 0.011 & 0.009 & 0.060 & 1.50 & 0.116 & 1.61 & 0.882 & 0.615 \\
\hline & & & 2017 & 33.6 & 18.4 & 0.002 & 0.019 & 0.001 & $<\mathrm{LOQ}$ & 0.022 & 1.06 & 0.152 & 1.21 & 0.557 & 0.502 \\
\hline & & & 2019 & 31.3 & 5.2 & $<\mathrm{LOQ}$ & 0.005 & $<\mathrm{LOQ}$ & $<\mathrm{LOQ}$ & 0.005 & 0.301 & 0.027 & 0.328 & 0.172 & 0.129 \\
\hline & \multirow[t]{3}{*}{ S2 } & \multirow[t]{3}{*}{ Rehlingen } & 2006 & 24.0 & 15.2 & 0.002 & 0.040 & 0.012 & 0.018 & 0.074 & 1.35 & 0.124 & 1.48 & 0.709 & 0.643 \\
\hline & & & 2017 & 33.6 & 20.8 & 0.003 & 0.040 & 0.001 & $<\mathrm{LOQ}$ & 0.045 & 1.64 & 0.143 & 1.78 & 1.15 & 0.482 \\
\hline & & & 2019 & 31.3 & 5.2 & $<\mathrm{LOQ}$ & 0.005 & $<L O Q$ & $<\mathrm{LOQ}$ & 0.005 & 0.314 & 0.026 & 0.340 & 0.233 & 0.081 \\
\hline
\end{tabular}




\begin{tabular}{|c|c|c|c|c|c|c|c|c|c|c|c|c|c|c|c|}
\hline \multirow[t]{2}{*}{ river } & \multirow[t]{2}{*}{ site } & \multirow[t]{2}{*}{ location } & \multirow[t]{2}{*}{ year } & \multirow{2}{*}{$\begin{array}{c}\text { Water } \\
\text { discharge } \\
{\left[\mathrm{m}^{3} / \mathrm{s}\right]}\end{array}$} & \multirow{2}{*}{$\begin{array}{l}\text { SPM } \\
\text { conc. } \\
{\left[\mathrm{g} / \mathrm{m}^{3}\right]}\end{array}$} & \multicolumn{5}{|c|}{ Data from target analysis $\left[\mathrm{kg} \mathrm{a}^{-1}\right]$} & \multicolumn{5}{|c|}{ Data from dTOP assay [kg a-1] } \\
\hline & & & & & & $\sum$ PFCA & ¿PFSA & $\begin{array}{l}\text { ¿Sulfon } \\
\text {-amides }\end{array}$ & $\sum$ diPAP & $\begin{array}{l}\text { ¿PFAS } \\
\text { Target }\end{array}$ & ¿PFCA & ¿PFSA & $\begin{array}{l}\text { ¿PFAS } \\
\text { dTOP }\end{array}$ & $\begin{array}{c}\sum \mathrm{C}_{4}-\mathrm{C}_{7} \\
\text { PFCA }\end{array}$ & $\begin{array}{c}\sum \mathrm{C}_{8}-\mathrm{C}_{18} \\
\text { PFCA }\end{array}$ \\
\hline \multirow[t]{12}{*}{ Elbe } & \multirow[t]{3}{*}{ E1 } & \multirow[t]{3}{*}{ Prossen } & 2005 & 344 & 16.7 & 0.163 & 0.841 & 0.072 & 7.36 & 8.44 & 18.7 & 1.58 & 20.3 & 8.69 & 9.99 \\
\hline & & & 2017 & 199 & 13.9 & 0.017 & 0.288 & 0.005 & 0.174 & 0.497 & 10.4 & 0.717 & 11.1 & 8.55 & 1.86 \\
\hline & & & 2019 & 199 & 16.2 & 0.044 & 0.516 & 0.014 & 0.079 & 0.676 & 20.7 & 1.67 & 22.4 & 18.3 & 2.46 \\
\hline & \multirow[t]{3}{*}{ E2 } & \multirow[t]{3}{*}{ Zehren } & 2005 & 354 & 11 & 0.116 & 0.646 & 0.089 & 2.73 & 3.58 & 13.1 & 1.48 & 14.6 & 6.86 & 6.23 \\
\hline & & & 2017 & 212 & 17 & 0.030 & 0.318 & $<\mathrm{LOQ}$ & 0.061 & 0.410 & 10.2 & 0.763 & 11.0 & 8.19 & 2.04 \\
\hline & & & 2019 & 204 & 22 & 0.057 & 0.441 & $<\mathrm{LOQ}$ & $<\mathrm{LOQ}$ & 0.497 & 10.2 & 1.04 & 11.2 & 8.27 & 1.92 \\
\hline & \multirow[t]{3}{*}{ E4 } & \multirow[t]{3}{*}{ Cumlosen } & 2005 & 682 & 23 & 1.04 & 3.08 & 0.474 & 5.79 & 10.4 & 33.8 & 6.44 & 40.2 & 14.1 & 19.7 \\
\hline & & & 2017 & 476 & 22 & 0.289 & 0.732 & 0.040 & 0.418 & 1.478 & 16.9 & 1.58 & 18.4 & 12.5 & 4.41 \\
\hline & & & 2019 & 382 & 28 & 0.150 & 0.686 & $<\mathrm{LOQ}$ & 0.171 & 1.01 & 13.3 & 1.25 & 14.5 & 10.0 & 3.26 \\
\hline & \multirow[t]{3}{*}{ E5 } & \multirow{3}{*}{$\begin{array}{c}\text { Blankenese } \\
*\end{array}$} & 2005 & 727 & 46 & 1.15 & 4.22 & 0.663 & 4.57 & 10.6 & 11.8 & 2.13 & 14.0 & 8.38 & 3.47 \\
\hline & & & 2017 & n.a. & 70.6 & n.d. & n.d. & n.d. & n.d. & n.d. & n.d. & n.d. & n.d. & n.d. & n.d. \\
\hline & & & 2019 & n.a. & 63.3 & n.d. & n.d. & n.d. & n.d. & n.d. & n.d. & n.d. & n.d. & n.d. & n.d. \\
\hline \multirow{3}{*}{ Saale } & \multirow{3}{*}{ Sa } & \multirow{3}{*}{ Wettin } & 2005 & 107 & 15 & 0.094 & 0.118 & 0.097 & 0.060 & 0.368 & 4.88 & 0.802 & 5.69 & 1.94 & 2.95 \\
\hline & & & 2017 & 73 & 18 & 0.041 & 0.035 & 0.007 & 0.030 & 0.117 & 2.41 & 0.236 & 2.64 & 1.47 & 0.932 \\
\hline & & & 2019 & 55.5 & 16 & 0.006 & 0.008 & 0.002 & $<\mathrm{LOQ}$ & 0.016 & 2.20 & 0.186 & 2.39 & 1.53 & 0.674 \\
\hline \multirow{3}{*}{ Mulde } & \multirow{3}{*}{$\mathrm{Mu}$} & \multirow{3}{*}{ Dessau } & 2005 & 90 & 6.6 & 0.089 & 0.069 & 0.022 & 1.48 & 1.66 & 3.06 & 0.195 & 3.25 & 1.29 & 1.77 \\
\hline & & & 2017 & 56 & 8.2 & 0.021 & 0.036 & 0.008 & 0.099 & 0.167 & 2.20 & 0.084 & 2.28 & 1.88 & 0.321 \\
\hline & & & 2019 & n.a. & 11 & n.d. & n.d. & n.d. & n.d. & n.d. & n.d. & n.d. & n.d. & n.d. & n.d. \\
\hline \multirow{6}{*}{ Danube } & \multirow{3}{*}{ D1 } & \multirow{3}{*}{ Ulm } & 2009 & 148 & 9.2 & 0.028 & 0.109 & 0.015 & $<\mathrm{LOQ}$ & 0.152 & 2.08 & 0.274 & 2.35 & 1.20 & 0.874 \\
\hline & & & 2017 & 149 & 14.3 & 0.020 & 0.109 & $<\mathrm{LOQ}$ & $<\mathrm{LOQ}$ & 0.129 & 2.33 & 0.356 & 2.68 & 1.68 & 0.643 \\
\hline & & & 2019 & n.a. & n.a. & n.d. & n.d. & n.d. & n.d. & n.d. & n.d. & n.d. & n.d. & n.d. & n.d. \\
\hline & \multirow{3}{*}{ D3 } & \multirow{3}{*}{ Jochenstein } & 2009 & 1433 & 14.2 & 0.700 & 0.789 & 0.053 & $<\mathrm{LOQ}$ & 1.74 & 14.7 & 1.62 & 16.3 & 7.32 & 7.41 \\
\hline & & & 2017 & 1307 & 24.1 & 0.488 & 0.713 & $<\mathrm{LOQ}$ & $<\mathrm{LOQ}$ & 1.310 & 15.0 & 1.41 & 16.4 & 11.6 & 3.39 \\
\hline & & & 2019 & 1446 & n.a. & n.d. & n.d. & n.d. & n.d. & n.d. & n.d. & n.d. & n.d. & n.d. & n.d. \\
\hline
\end{tabular}

* Blankenese lies in the tidal zone of the Elbe which makes it difficult to measure the discharges; n.a.: not available; n.d.: not determined because no data for discharge and/or SPM concentration were available for 2017 and 2019. Bold: loads higher in 2019 than in 2005. 


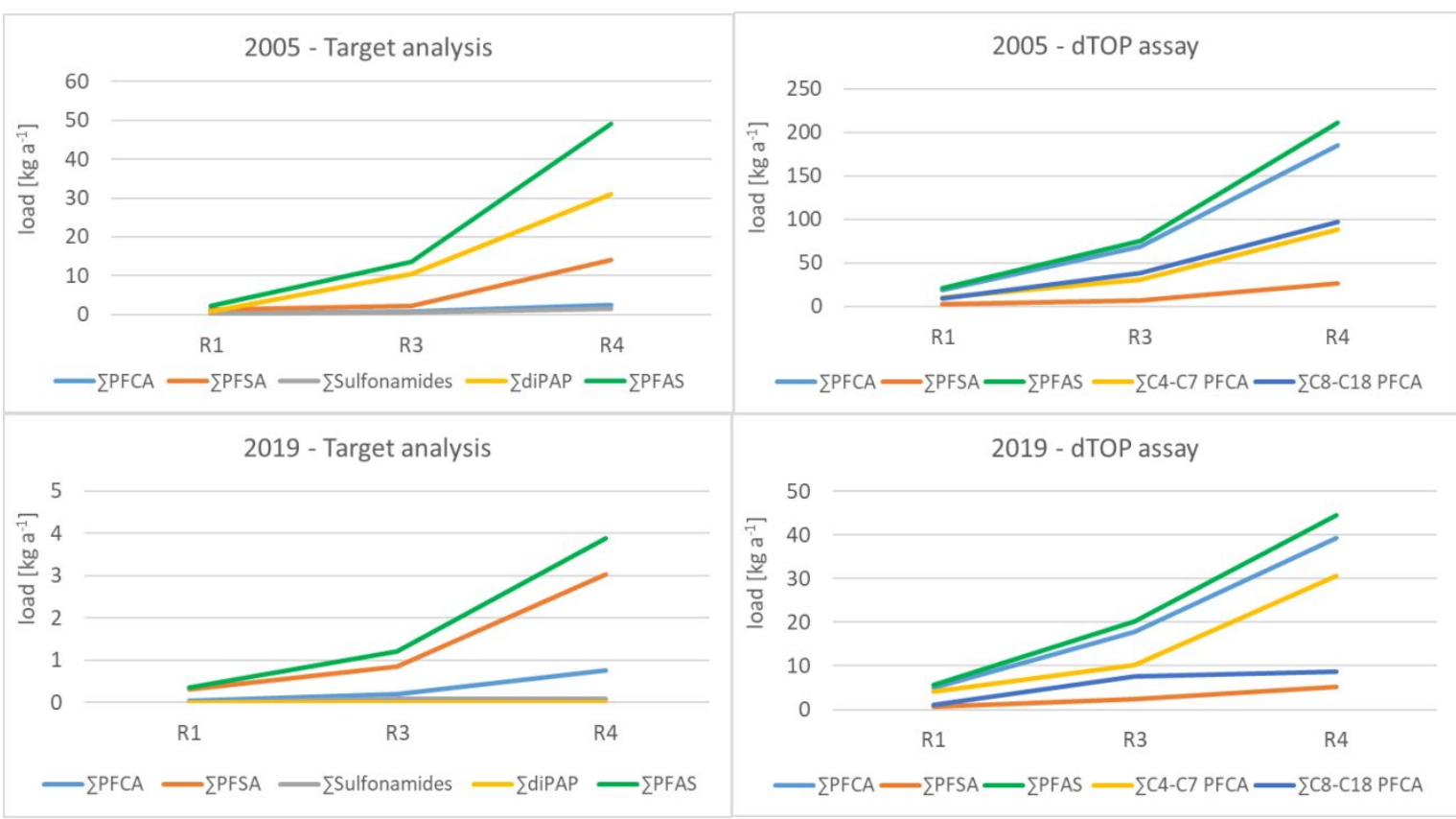

Fig. S14: Annual PFAS loads ( $\mathrm{kg} \mathrm{a}^{-1}$ ) carried by suspended particulate matter (SPM) in the Rhine in 2005 and 2019. Calculations based on dry weight concentrations determined by target analysis (LOQ: $0.05-0.5 \mu \mathrm{g} \mathrm{kg}{ }^{-1}$, left panels) and dTOP assay (LOQ: $1.0 \mu \mathrm{g} \mathrm{kg}^{-1}$, right panels) and data available from the International Commission for the Protection of the Rhine (ICPR). Note the different scaling of the $y$-axis.

R1: Rhine-Weil, R3: Rhine-Koblenz; R4: Rhine-Bimmen.

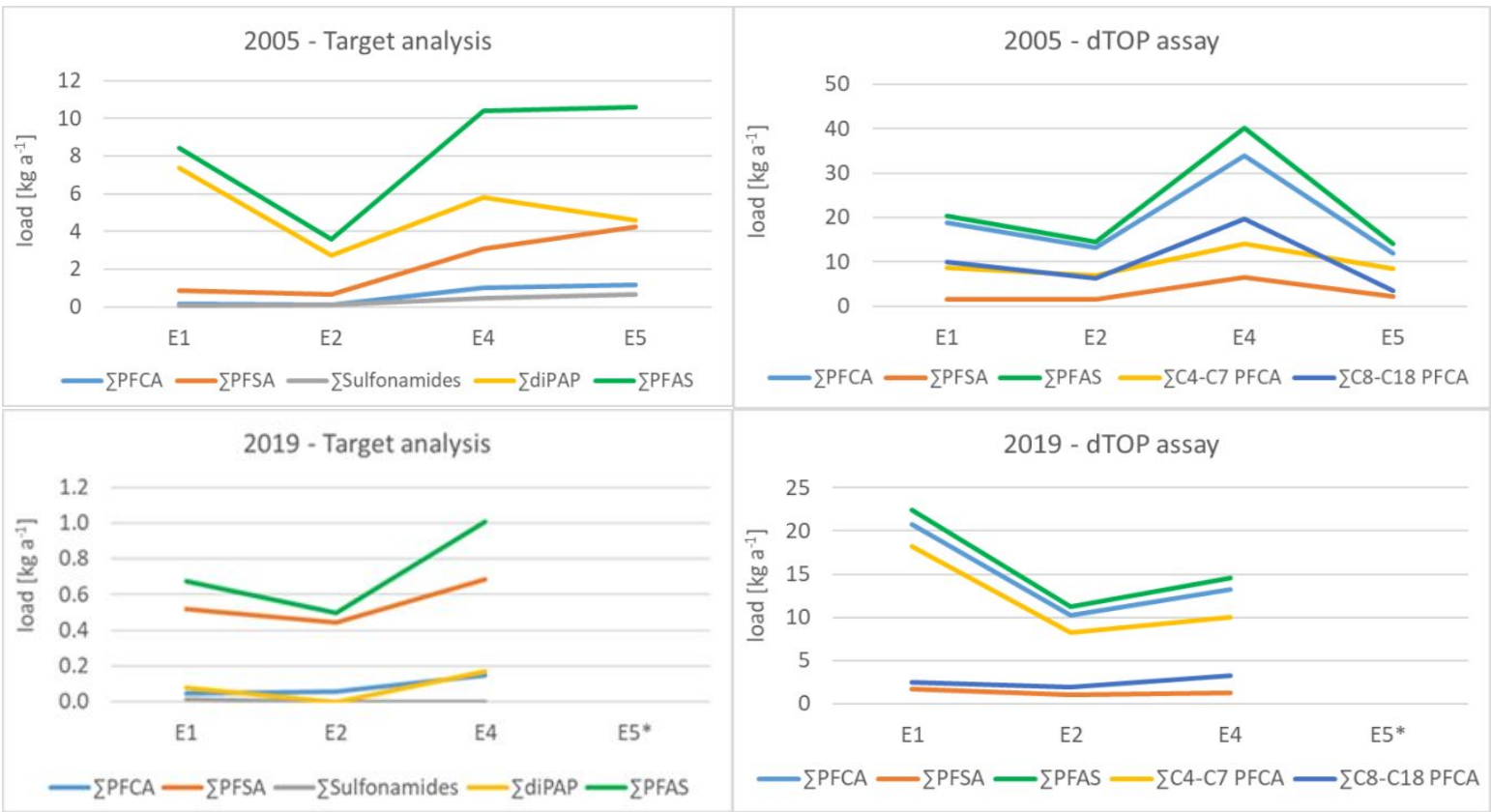

Fig. S15: Annual PFAS loads ( $\mathrm{kg} \mathrm{a}^{-1}$ ) carried by suspended particulate matter (SPM) in the Elbe in 2005 and 2019. Calculations based on dry weight concentrations determined by target analysis (LOQ: $0.05-0.5 \mu \mathrm{g} \mathrm{kg}{ }^{-1}$, left panels) and dTOP assay (LOQ: $1.0 \mu \mathrm{g} \mathrm{kg}^{-1}$, right panels) and data available from the International Commission for the Protection of the Elbe (ICPER). Note the different scaling of the $y$-axis. E5*: no calculation possible. E1: Elbe-Prossen; E2: Elbe-Zehren; E4: Elbe-Cumlosen; E5: Elbe-Blankenese. 


\section{References}

1. Kotthoff, M.; Fliedner, A.; Rüdel, H.; Göckener, B.; Bücking, M.; Biegel-Engler, A.; Koschorreck, J., Perand polyfluoroalkyl substances in the German environment - Levels and patterns in different matrices. Science of The Total Environment 2020, 740, 140116.

2. Göckener, B.; Eichhorn, M.; Lämmer, R.; Kotthoff, M.; Kowalczyk, J.; Numata, J.; Schafft, H.; LahrssenWiederholt, M.; Bücking, M., Transfer of Per- and Polyfluoroalkyl Substances (PFAS) from Feed into the Eggs of Laying Hens. Part 1: Analytical Results Including a Modified Total Oxidizable Precursor Assay. Journal of Agricultural and Food Chemistry 2020.

3. Fliedner, A.; Lohmann, N.; Rüdel, H.; Teubner, D.; Wellmitz, J.; Koschorreck, J., Current levels and trends of selected EU Water Framework Directive priority substances in freshwater fish from the German environmental specimen bank. Environmental pollution (Barking, Essex : 1987) 2016, 216, 866-876. 